\title{
Improved design of threaded connections by autofrettage in aluminium compounds for cyclic high pressure loading: design calculations and experimental verification
}

\author{
Stephan Sellen ${ }^{\mathrm{a}}$, Stefan Maas ${ }^{\mathrm{a}}$, Thomas Andreas ${ }^{\mathrm{b}}$, Peter Plapper $^{\mathrm{a}}$, Arno Zürbes ${ }^{\mathrm{c}}$, \\ Daniel Becker ${ }^{\mathrm{b}}$ \\ a University of Luxembourg, Campus Kirchberg, L-1359, Luxembourg \\ ${ }^{b}$ Rotarex S.A., Lintgen, L-7440, Luxembourg \\ ${ }^{\mathrm{C}}$ FH-Bingen, D-55411, Germany
}

\begin{abstract}
Threaded connections in an aluminium valve body under high internal swelling pressure are investigated. A static straining process called autofrettage leads to an improved fatigue behaviour of the aluminium component, while normally the threaded connections are unloaded during this autofrettage. But by unloading the thread during autofrettage the first loaded thread flank became the weakest point of this valve component. This effect is analyzed with non-linear finite element simulations, FKM guideline for fatigue assessment and by experimental testing. The analytical and experimental parts match very well and it can be shown that a well-designed autofrettage without unloading the threaded connection is helpful for the aluminium thread and extends its fatigue lifetime, as compressive residual stresses and an equalized stress distribution over the thread flanks can be generated. Finally different materials were chosen for the plug or screw and this effect for cyclic loading is shortly analyzed.
\end{abstract}

\section{Keywords}

Fatigue of threaded connections in aluminium components, non-linear finite element simulation, FKM guideline, high pressure cyclic loading. 


\section{Content}

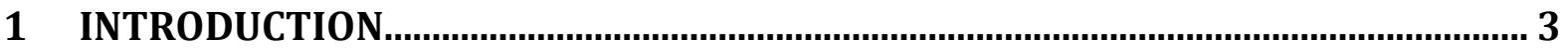

2 AUTOFRETTAGE - A METHOD TO INCREASE THE FATIGUE STRENGTH .............. 4

3 FATIGUE BEHAVIOUR OF THREADED CONNECTIONS AND THE INFLUENCE OF PRECEDING SINGULAR PLASTIC YIELDING ............................................................... 5

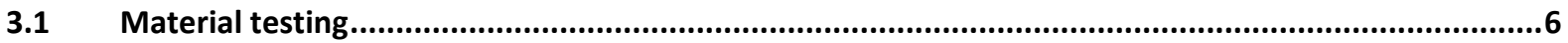

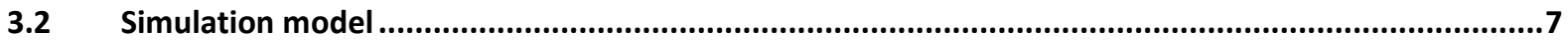

3.3 Load distribution in the root of the valve thread under cyclic internal pressure loading ....................9

3.4 Fatigue assessment based on linear elastic stresses according to FKM guideline ............................10

3.5 Calculated (Non-Linear FEM) Load distribution for cyclic pressure loading after autofrettage with $\mathbf{3 0 0}$ $\mathrm{MPa} \quad 12$

3.6 Fatigue assessment according to FKM guideline for cyclic loading after Autofrettage with $300 \mathrm{MPa} 14$

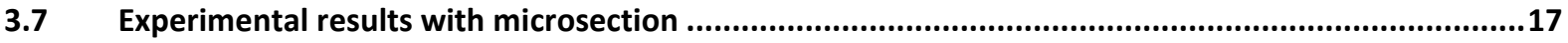

4 SENSITIVITY ANALYSIS

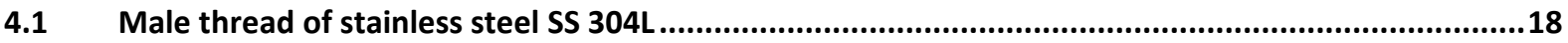

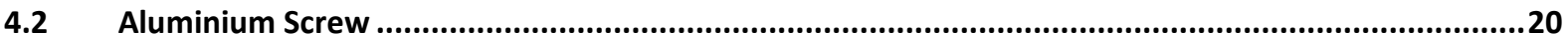

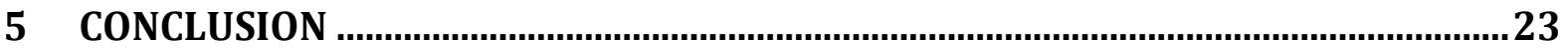

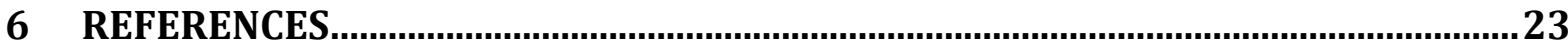




\section{Introduction}

Future lightweight design requirements challenge the usage of aluminium for gaseous energy storage. As an example Figure 1 shows the structure of such a valve:

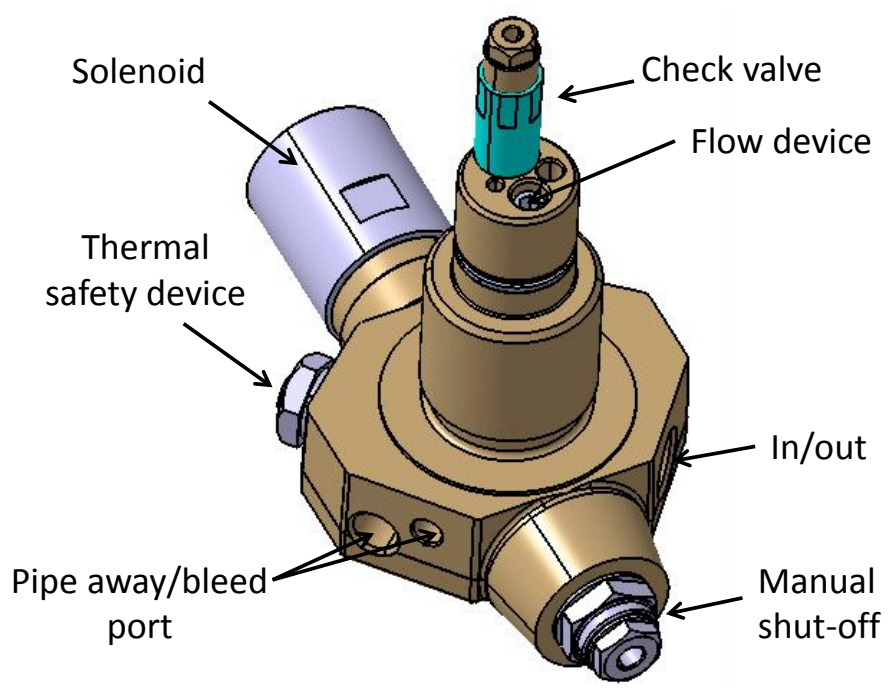

Figure 1: Typical design of a valve for gaseous applications

The approximately hand-sized valve body connects with several internal crossing bore holes the different functions of the valve, as indicated in Figure 1. According to the relevant testing guideline [1] the valve bodies have to withstand a cyclic hydraulic pressure test of $N=150,000$ cycles under nearly swelling load with a maximum pressure of $87.5 \mathrm{MPa}$.

In order to achieve the required number of cycles for the given cyclic pressure range, it was necessary to apply the autofrettage process to the inner contour of the aluminium valve body because the cyclic tests revealed a rapid crack growth starting at the sharp edged bore crossings in the aluminium valve body, which led to a global failure after less than 90,000 cycles. By autofrettage the fatigue resistance of the bore crossings was increased to more than 1 million cycles without a global failure [4] and thus the requirements of the testing guideline were fulfilled.

However the cyclic testing was continued and cracks occurred in the valve body at the threatened end plug of the solenoid with a rather large tightening diameter (M24x1 with 9 carrying threads) and led to a global failure after more than 400,000 cycles (Table 1 ).

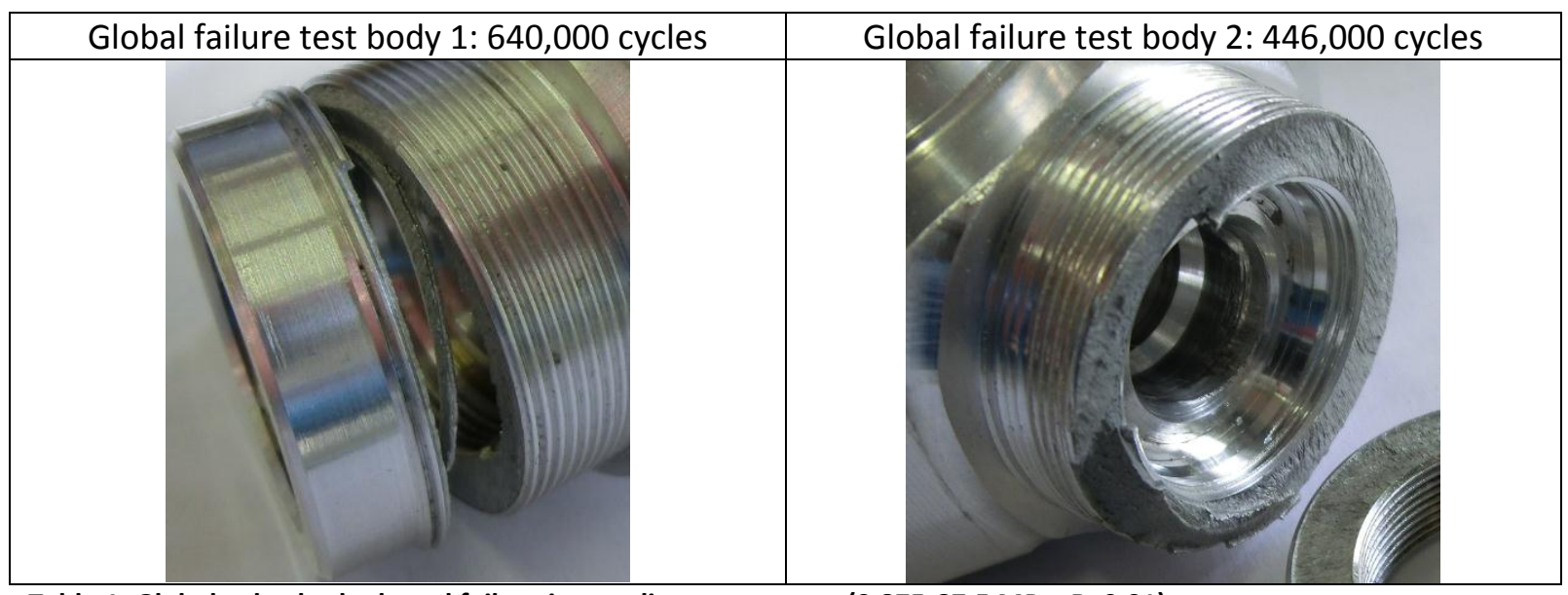

Table 1: Global valve body thread failure in a cyclic pressure test (0.875-87.5 $\mathrm{MPa} ; \mathrm{R}=\mathbf{0 . 0 1 )}$ 
It was visible that the crack plane was growing perpendicular to the first load-bearing thread flank of the screwed in end plug. Though the target according to the testing guideline was reached, the experiments showed that this load-bearing thread flank was now the weakest point of the tested valve.

In the following the fatigue resistance is estimated with and without autofrettage and based on linear and on non-linear finite element simulations followed by fatigue calculations. Finally the results are compared to experimental cyclic tests.

\section{Autofrettage - a method to increase the fatigue strength}

In order to fulfil the requirements of the testing guideline ( $N=150,000$ with $\Delta p \approx 87.5 \mathrm{MPa}$ ) an autofrettage pressure was applied to the valve body. The basics and the effect of this method are described for example in the work of Schön et al. [2] and Seeger et al [3]. Briefly summarized autofrettage means a very high unique static pressure load (load step (LS1); Figure 2) leading to local plastification at the hot spots while due to the steep gradient the farer regions are only elastically stressed at rather low level. After release of the high autofrettage pressure the elastically stressed farer regions can induce compressive stresses in the plastically deformed closer regions (load step or LS2, Figure 2).

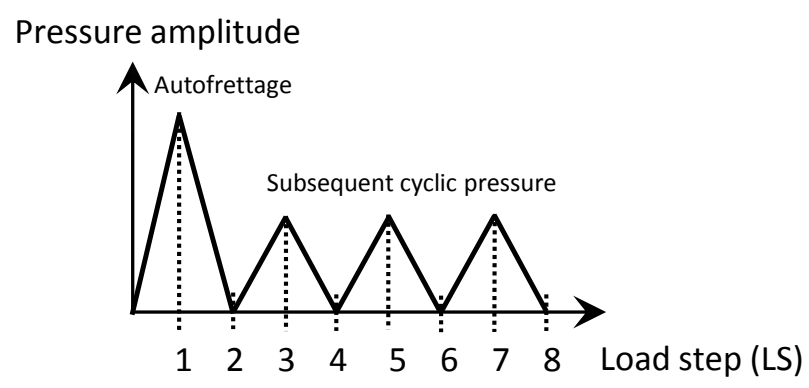

Figure 2: Schematic load steps of autofrettage and subsequent cyclic pressure loading

The subsequent cyclic loading (LS3, LS4, LS5...) is at a far lower pressure level than the autofrettage pressure and hence ideally not leaving the compressive pre-stress range at the inner surface. Also the HAIGH-diagram illustrates that a shift of the mean stress by autofrettage alters the allowable stress amplitude from $\sigma_{a, i n}$ to $\sigma_{a, a f}$ when the initial mean stress $\sigma_{m, i n}$ moves by autofrettage to negative values $\sigma_{\mathrm{m}, \text { af }}$ (Figure 3 ).

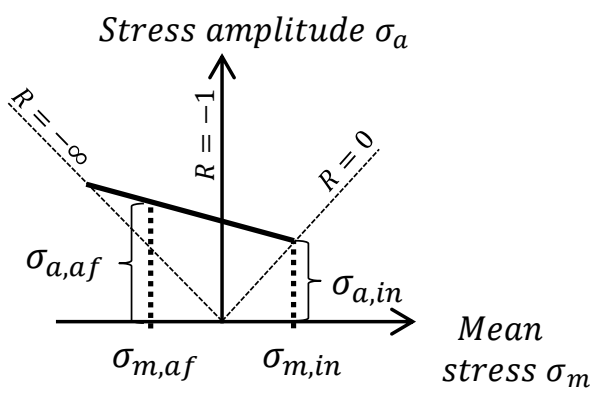

Figure 3: Schematic illustration of the autofrettage-effect in the HAIGH-diagram 
In previous works [4] we proposed rules and finally chosed $300 \mathrm{MPa}$ as an appropriate autofrettage pressure for the internal pressurized aluminium geometry $\left(90^{\circ}\right.$-bore intersection) to increase fatigue resistance.

Before applying this high autofrettage pressure one has to check if the threaded plugs with a quite large diameter could be overloaded. Therefore hydraulic cylinders are usually installed in order to unload the plugs during the autofrettage process. This is a typical and known method used for the tubes of high pressure diesel common rail injection systems. It is shown for example in the patent of Maximator [5], where the external sealing forces of the end plugs rise proportionally with the autofrettage pressure (Figure 4). Through one of the end plugs the inner of the work piece is filled with the medium and afterwards the autofrettage pressure is applied. In order to guarantee the tightness of the sealing cones without overloading them, the external forces on the end plugs are proportionally increased to the internal pressure and always higher than the force generated by the internal pressure at the opposite side.

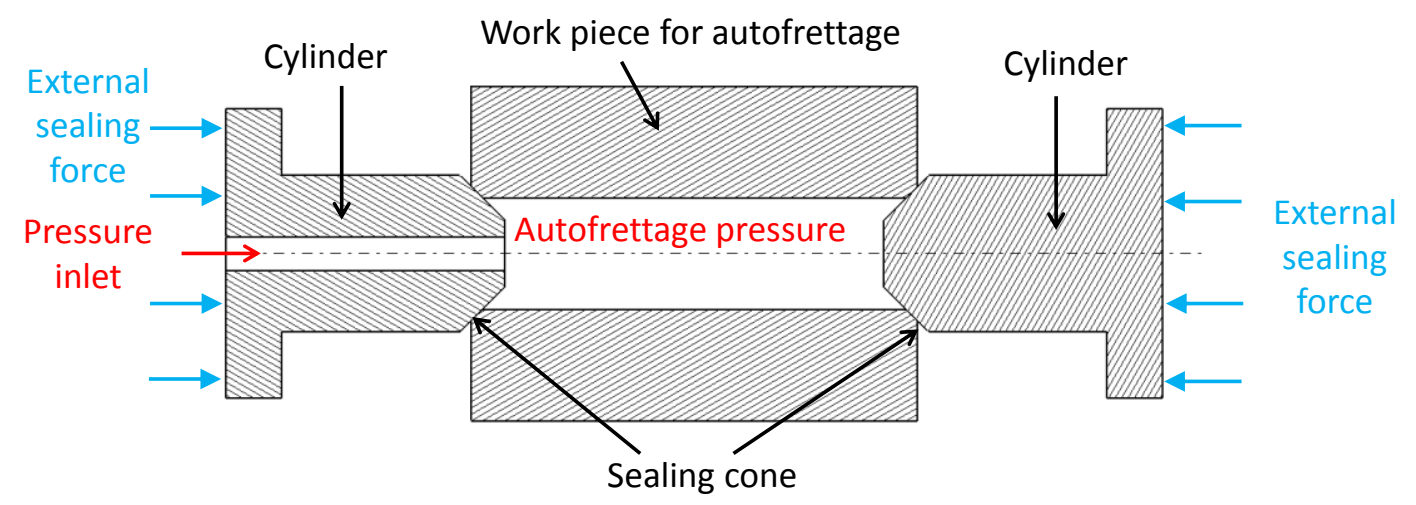

Figure 4: Schematic illustration of autofrettage process of a work piece with external bracing by two end plugs

With the help of this process the threads were not highly loaded during the autofrettage of the valve body. After a bit more than 400,000 cycles as already shown in Table 1 the first loaded thread flank completely failed due to fatigue crack growth. The root of the thread flank is a notch leading to high stress concentration due to the mechanical loading. A unique static overload of this point with plastic yielding could also induce residual compressive stresses and hence have a positive effect on subsequent cyclic loading. Practically this means that the end plugs should not be unloaded and protected during the autofrettage of the valve body and thus increasing the fatigue lifetime.

This idea is subsequently studied with the help of linear-elastic and non-linear finite element simulations and subsequent fatigue lifetime assessment based on local stresses in the roots of the thread. Finally it is compared to experimental testing results.

\section{Fatigue behaviour of threaded connections and the influence of preceding singular plastic yielding}

Wang et al [6] studied the load distribution for a yielding threaded connection under static loading with a simplified spring model. As the outer threads carry the highest loads yielding starts there and leads to an increased loading of the flank next to the yielding one(s). Cetin et al [7] and Schneider et al [8] studied the fatigue behaviour of threaded components with local fatigue concepts for the critical thread flank, but without consideration of a possible preceding singular plastic yielding. Korin 
et al [9] studied experimentally the fatigue life and crack growth in a tension bolt-nut threaded connection, but also without a prior static overload. Korin et al [10] propose an innovative technique to improve the fatigue resistance of rotary shouldered connections used in oil drilling industry by application of a defined over-torque and subsequent reduction to the nominal value. In general the experiments increased the fatigue life, though in some cases with high over-torque a reduced lifetime was measured. Furthermore it is known that the relation of a tightening torque and an axial force is rather imprecise as friction coefficients have to be estimated and are even not constant values in practise.

Summarising we can state that yielding of the critical thread flank leads to a load increase of the neighbouring flank. A unique static overload seems to have a positive effect on the fatigue lifetime. In order to predict the fatigue lifetime of a pre-stressed thread, the changes of the mean stress values and the stress amplitudes are of particular interest. There is no evidence about the main influencing factors and the best choice material combination of male and female thread material. In our case only aluminium was used for the female (nut) thread, which is chosen for reasons of lightweight design and machinability.

\subsection{MATERIAL TESTING}

In order to perform non-linear elastic-plastic finite element simulations for the static loading the stress-strain characteristics of the used materials was needed: stainless steel (AISI 304) for the screwed plug and aluminium (AW-6082-T6) for the valve body. Strain controlled tensile tests were done and the stress was calculated with the force data of a load cell and the known cross section and with the strain measured by an extensometer.

Figure 5 shows the stress-strain behaviour for the two used materials.

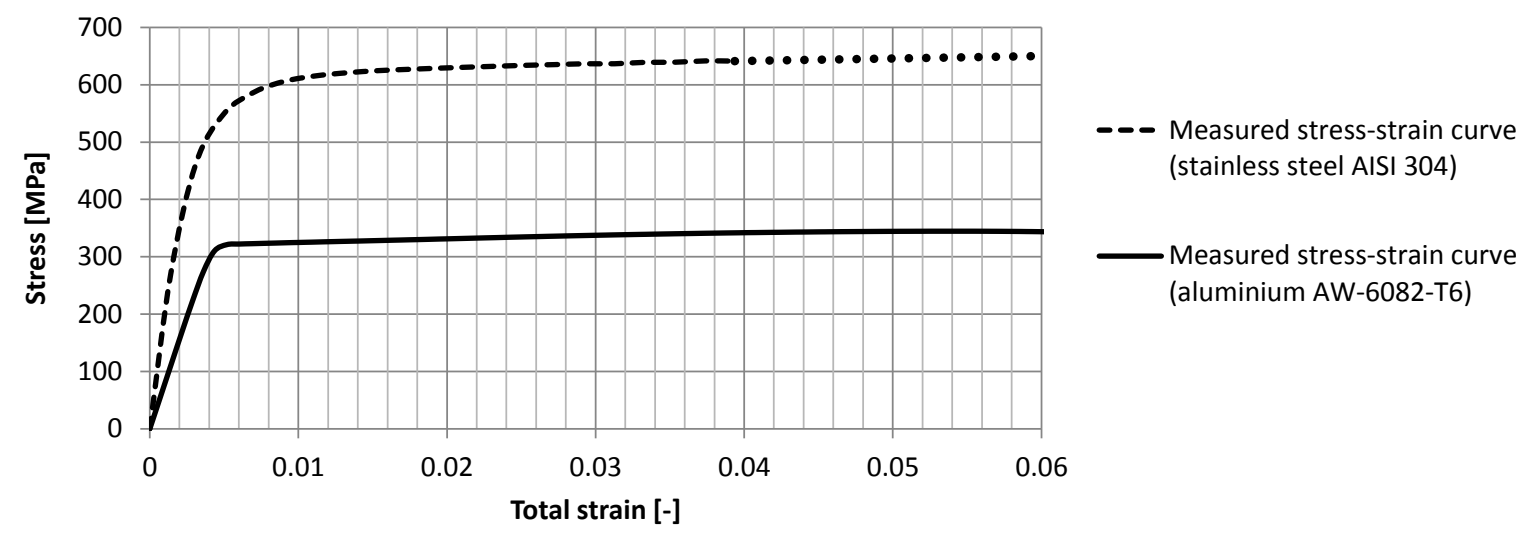

Figure 5: Measured static stress-strain curves for stainless steel AISI 304 and aluminium AW-6082-T6

The aluminium tensile specimen shows a modulus of elasticity $E=74,600 \mathrm{MPa}$, a yield strength of $R_{p}=323 \mathrm{MPa}$, an ultimate tensile strength of $R_{m}=345 \mathrm{MPa}$ and a fracture elongation of $A=7.1 \%$ and may be approximated by bilinear material behaviour. For the stainless steel a modulus of elasticity $E=193,300 \mathrm{MPa}$, a yield strength of $R_{p}=545 \mathrm{MPa}$ and an ultimate tensile strength of $R_{m}=642 \mathrm{MPa}$ were measured.

The used non-linear material model was based on the above mentioned tests, why the measured static stress-strain curves $\left(\sigma_{\text {ing }}, \varepsilon_{\text {ing }}\right)$ of the tensile specimens in Figure 5 were converted to 
logarithmic strain $\varepsilon_{\log }$ and real stress $\sigma_{\text {real }}$ curves. This conversion helps to correct the effect of specimen elongation and of area reduction in the tensile test and thus leads to the true or real stress or strain values. It is based on the following equations, which are recommended by Rust [11]:

$$
\begin{gathered}
\varepsilon_{\text {log }}=\ln \left(1+\varepsilon_{\text {ing }}\right) \\
\sigma_{\text {real }}=\sigma_{\text {ing }}\left(1+\varepsilon_{\text {ing }}\right)
\end{gathered}
$$

In case of inverse plastifications the aluminium AW-6082-T6 shows very good accordance in experimental Bauschinger-tests [12] with the idealized bilinear kinematic hardening material model (material model: see ANSYS [13]) [4].

\subsection{SIMULATION MODEL}

For the simulation with the software ANSYS of the rotationally symmetric connection between the screwed plug and the valve body, a $1^{\circ}$-segment of the threaded connection (metric thread: $\mathrm{M} 24 \times 1$ ) was selected for the finite element simulation (Figure 6). The radial O-ring gasket in Figure 6 is only shown for better understanding but is not included in the simulation model. It should be noted that for combination of cyclic fluctuating high pressure with an aluminium valve body it is important to design the pressure loaded area as small as possible.

Valve body with screwed plug

(3D section view)
Reduced simulation model:

$1^{\circ}$-segment with detailed thread modelling (M24×1)

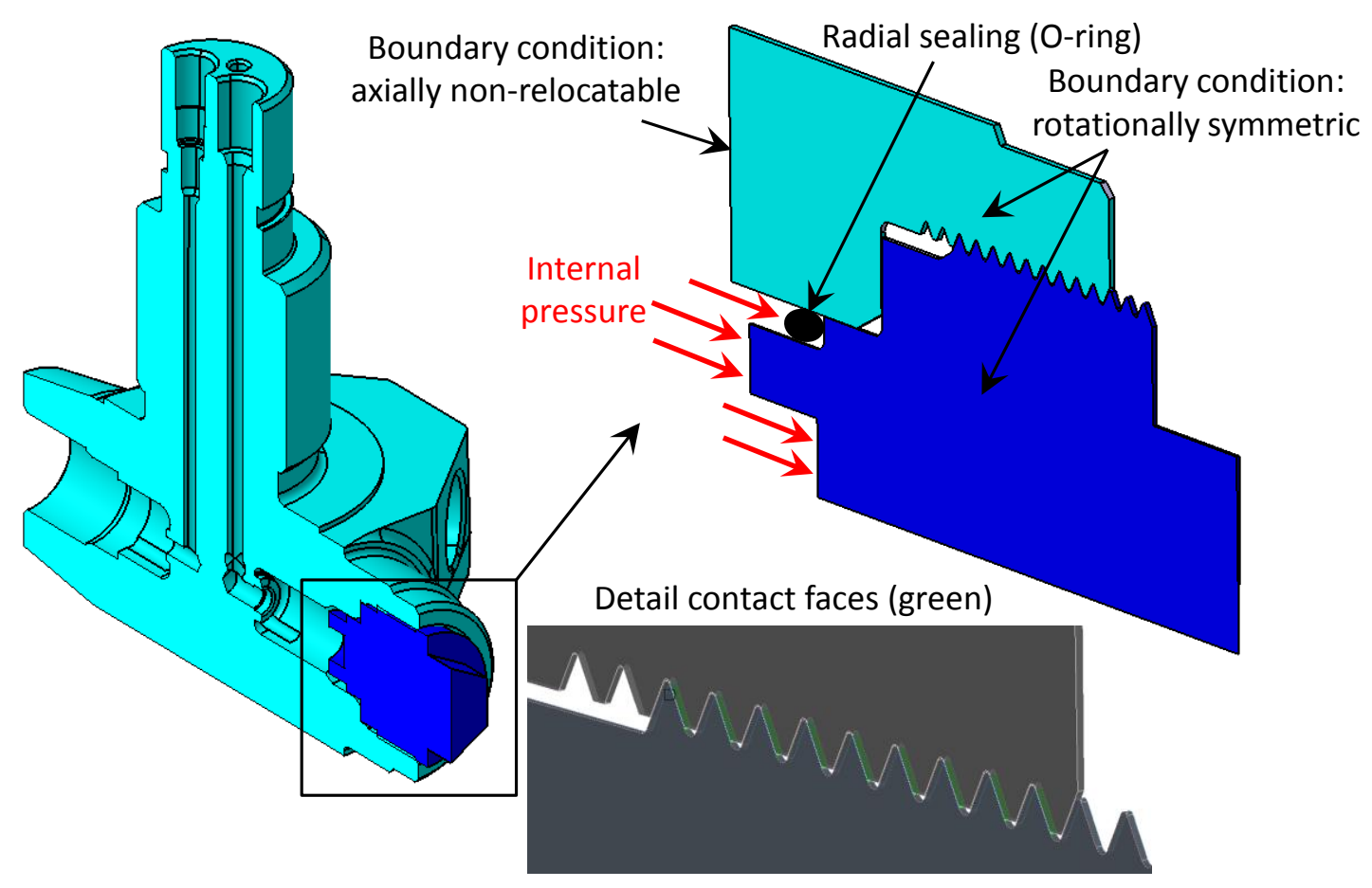

Figure 6: 3D section view of the threaded connection (left) and $1^{\circ}$-segment with modelled thread M24x1

As shown in Figure 6 rotational symmetry for the lateral cut faces of the $1^{\circ}$-segment (valve body and plug) was defined. The valve body was cut far away from the threaded connection in the thickwalled area as shown in Figure 6, so that an influence on the occurring stresses in the thread was excluded. The cut surface was axially fixed, i.e. considered non-relocatable as indicated in Figure 6. Also the influence of the circumferential stresses at the thick-walled area due to the pressure 
loading of the valve bore on the thread stresses was studied and may be neglectable because of the large distance to the threaded zone.

The finite element mesh was locally refined at the contact region and at the root of the thread with an element length of approximately $8 \mu \mathrm{m}$, i.e. the root radius has more than 10 elements (Figure 7).

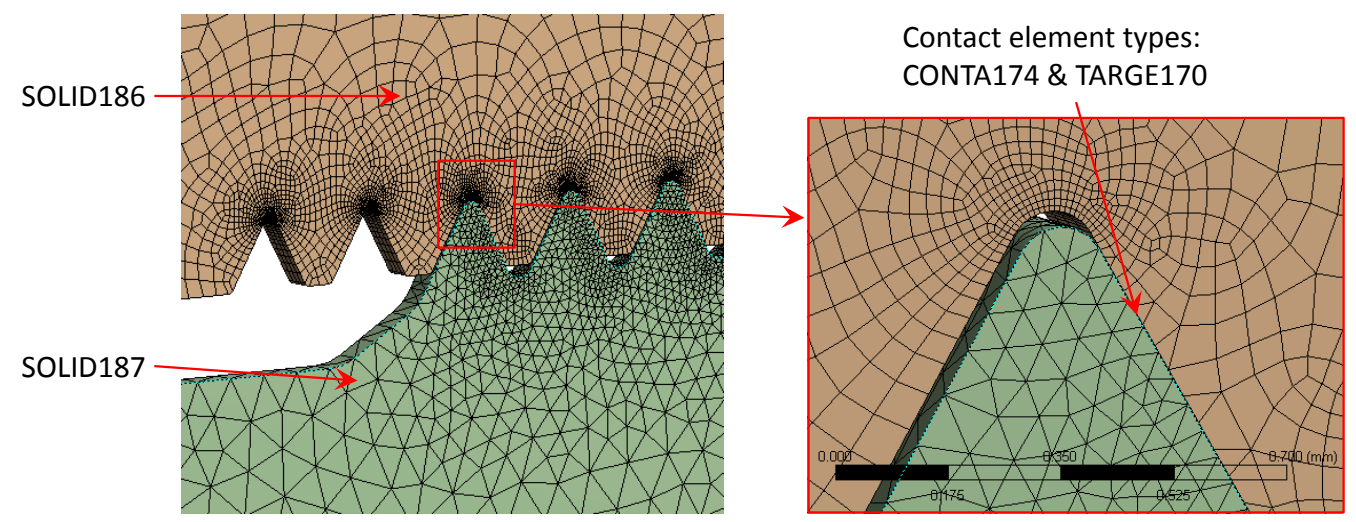

Figure 7: Mesh of the finite element model with local refinement in the root of the valve body thread and the contact region

The contact region was additionally meshed with contact elements CONTA174 (plug) and TARGE170 (valve body) and a typical friction coefficient of $\mu=0.2$ for non-lubricated thread flanks was defined between the interacting parts. The backside flanks of the thread were not considered for the contact as the axial force acts only in one direction. Figure 7 shows no gap between the contact flanks to avoid numerical instability and a gap of some hundredths of a millimetre at the backside resulting from an ideally modelled thread-geometry. This model is also used for the simulation of the autofrettage process in the first three load steps (Figure 2). The occurring plasticity does not lead to a contact of the backside flanks because the plastic thread deformations are far too small compared to the gap width.

The pre-stressing due to the torque-up was neglected because the tightening torque was very low with $\mathrm{M}=15 \mathrm{Nm}$.

For the non-linear simulations the measured stress-strain curves were corrected by equations (1) and (2) and a bilinear kinematic hardening model for the aluminium alloy (modulus of elasticity $E=74,600 \mathrm{MPa}$; tangent modulus $\mathrm{T}=820 \mathrm{MPa}$; yield strength $\mathrm{R}_{\mathrm{p}}=323 \mathrm{MPa} ; \mathrm{A}=7.1 \%$ ) and a non-linear kinematic hardening material model for the stainless steel plug $(E=193,300 \mathrm{MPa})$ with the corrected stress-strain data were chosen.

Unlike the linear-elastic finite element simulation with a constant stiffness matrix, yielding leads to a solution (or strain)-dependent stiffness matrix, which implies an iterative calculation, e.g. with the help of the Newton-Raphson-procedure for the displacement increments caused by the incremental increase of the external load. The Von-Mises yield criterion was chosen to distinguish between the pure elastic and the elastic-plastic state. The kinematic hardening model including the associated flow rule was selected, meaning that plastic strains occur in a direction normal to the yielding surface. Yielding leads to a shifted yield surface, i.e. a direction-dependent change of the material's proportional limit after a primary plastic deformation, which is also known as the Bauschinger effect (see ANSYS: nonlinear kinematic hardening) [13]. 


\subsection{LOAD DISTRIBUTION IN THE ROOT OF THE VALVE THREAD UNDER CYCLIC INTERNAL PRESSURE}

\section{LOADING}

The maximum operating pressure of $87.5 \mathrm{MPa}$ causes the highest stress values at the root of the first load carrying thread flank (Figure 8). There is only a small zone of plastic straining at the root of less than $50 \mu \mathrm{m}$ length, i.e. only the female aluminium root yields a little bit.

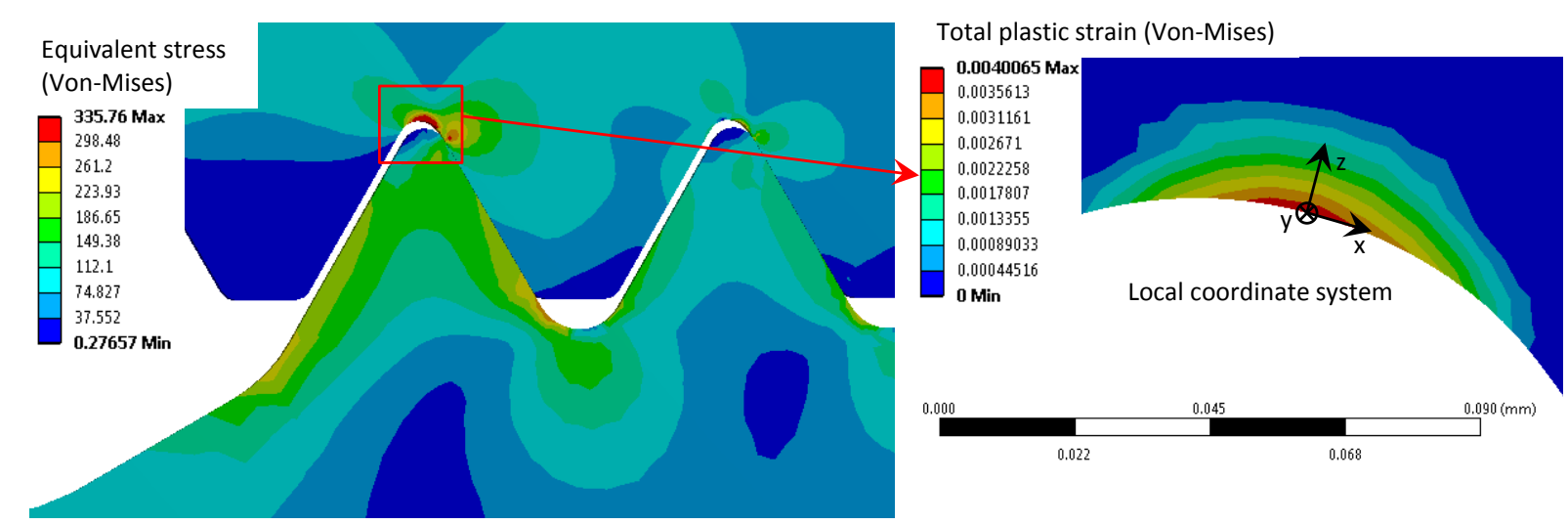

Figure 8: Results of non-linear Finite Element Method (FEM) analysis for a pressure load of 87.5 MPa: total equivalent stress and plastic strain in Load-Step 3 (LS3) (Von-Mises)

In addition to the non-linear analysis a linear-elastic finite element simulation of the three principal stress ranges including their mean stress values at the hot spot (directions see local coordinate system in Figure 8) was done. The first nine carrying thread roots are listed for the aluminium compound for a cyclic pressure range of $p=0.875-87.5 \mathrm{MPa}(R=0.01)$. The highest values occur of course at in the first carrying thread flank in $\mathrm{x}$-direction, which corresponds approximately to the rotational symmetry axis direction. Table 2 reveals that the threads $4,5, \ldots, 9$ are nearly without load. 
Normal stress $[\mathrm{MPa}]$ in $\mathrm{x}-$ direction $\left(\sigma_{1}\right)$ for cyclic pressure range (0.875-87.5 $\mathrm{MPa} ; \mathrm{R}=0.01$ ) (linear-elastic stresses)

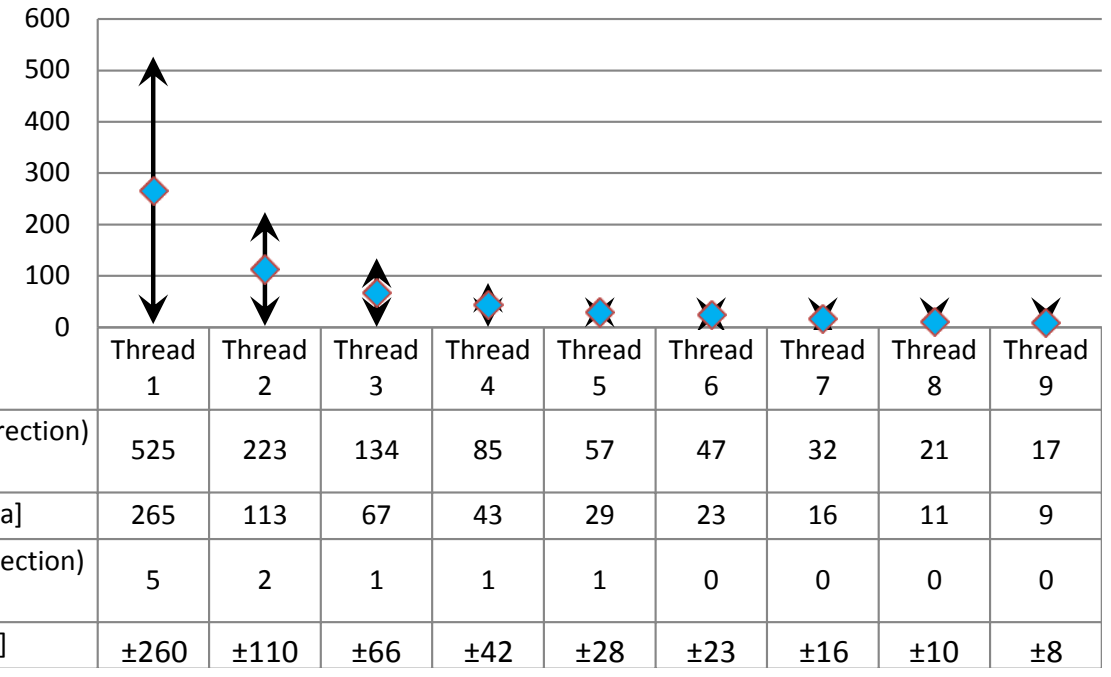

\begin{tabular}{|c|c|c|c|c|c|c|c|c|c|}
\hline $\begin{array}{c}\text { Maximum normal stress (x-direction) } \\
{[\mathrm{MPa}]}\end{array}$ & 525 & 223 & 134 & 85 & 57 & 47 & 32 & 21 & 17 \\
\hline Mean stress (x-direction) [MPa] & 265 & 113 & 67 & 43 & 29 & 23 & 16 & 11 & 9 \\
\hline $\begin{array}{l}\text { Minimum normal stress (x-direction) } \\
{[\mathrm{MPa}]}\end{array}$ & 5 & 2 & 1 & 1 & 1 & 0 & 0 & 0 & 0 \\
\hline Stress amplitude $(\Delta \sigma / 2)[\mathrm{MPa}]$ & \pm 260 & \pm 110 & \pm 66 & \pm 42 & \pm 28 & \pm 23 & \pm 16 & \pm 10 & \pm 8 \\
\hline
\end{tabular}

Normal stress [MPa] in ydirection $\left(\sigma_{2}\right)$ for cyclic pressure range $(0.875-87.5$ MPa; $R=0.01$ ) (linear-elastic stresses)

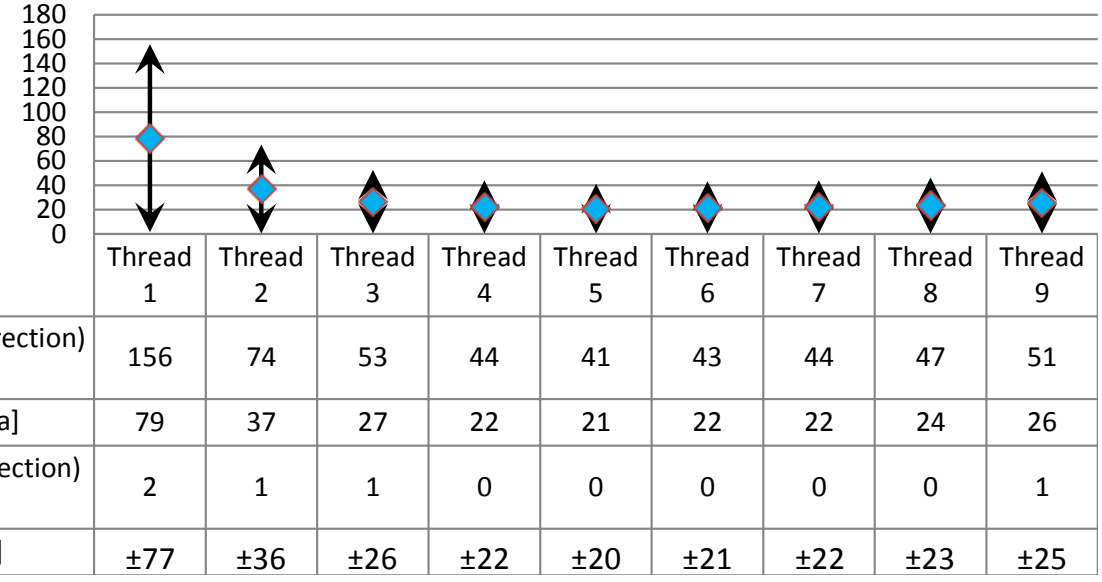

Stress amplitude $(\Delta \sigma / 2)[\mathrm{MPa}]$

Normal stress [MPa] in zdirection $\left(\sigma_{3}\right)$ for cyclic pressure range (0.875-87.5 $\mathrm{MPa} ; \mathrm{R}=0.01$ ) (linear-elastic stresses)

\begin{tabular}{|c|c|c|c|c|c|c|c|c|c|}
\hline \multirow{2}{*}{$\begin{array}{llll}2+1 & 0\end{array}$} & & & & & & & & & \\
\hline & $\begin{array}{c}\text { Thread } \\
1\end{array}$ & $\begin{array}{c}\text { Thread } \\
2\end{array}$ & $\begin{array}{c}\text { Thread } \\
3\end{array}$ & $\begin{array}{c}\text { Thread } \\
4\end{array}$ & $\begin{array}{l}\text { Thread } \\
5\end{array}$ & $\begin{array}{l}\text { Thread } \\
\quad 6\end{array}$ & $\begin{array}{l}\text { Thread } \\
\quad 7\end{array}$ & $\begin{array}{c}\text { Thread } \\
8\end{array}$ & $\begin{array}{c}\text { Thread } \\
9\end{array}$ \\
\hline $\begin{array}{c}\text { Maximum normal stress (z-direction) } \\
{[\mathrm{MPa}]}\end{array}$ & 2 & 1 & 1 & 1 & 1 & 1 & 0 & 0 & 0 \\
\hline Mean stress (z-direction) [MPa] & 1 & 1 & 0 & 0 & 0 & 0 & 0 & 0 & 0 \\
\hline $\begin{array}{l}\text { Minimum normal stress (z-direction) } \\
{[\mathrm{MPa}]}\end{array}$ & 0 & 0 & 0 & 0 & 0 & 0 & 0 & 0 & 0 \\
\hline Stress amplitude $(\Delta \sigma / 2)[\mathrm{MPa}]$ & \pm 1 & \pm 1 & \pm 0 & \pm 0 & \pm 0 & \pm 0 & \pm 0 & \pm 0 & \pm 0 \\
\hline
\end{tabular}

Table 2: Linear-elastic load distribution in the female aluminium thread roots (without previous overloading)

Based on the linear elastic principal stress ranges $\Delta \sigma_{i}$ for the given cyclic loading, a fatigue assessment was done according to the FKM guideline [14] to determine the allowable number of cycles prior to crack initiation.

\subsection{FATIGUE ASSESSMENT BASED ON LINEAR ELASTIC STRESSES ACCORDING TO FKM GUIDELINE}

According to the FKM guideline, the three principal stress amplitudes $\Delta \sigma_{i} / 2$ have to be considered at the hot spot in case of complex geometries for the fatigue assessment. Based on linear-elastic finite 
element simulations of a structural component, the load factors for the three principal stresses are determined according equation (3) and summed up to an equivalent loading factor according to the VON-MISES equivalent stress hypothesis for ductile materials (explanation of all coefficients see Table 3).

$$
a_{B K, \sigma_{i}}=\frac{\sigma_{a i} \cdot\left[1+\frac{1}{K_{f}} \cdot\left(\frac{1}{K_{R, \sigma}}-1\right)\right] \cdot j_{g e s}}{K_{A K, \sigma} \cdot K_{B K, \sigma} \cdot n_{\sigma i} \cdot f_{w, \sigma} \cdot R_{m}} \leq 1
$$

For a three-dimensional geometry the maximum stress gradients $\left(G_{\sigma i}\right)$ for the first two principal stresses $\left(\sigma_{1}\right.$ and $\left.\sigma_{2}\right)$ parallel to the surface have to be considered normal to the surface. Hence the evaluation path s starts at the assessed point at the geometry surface and is directed normal to the surface towards the inner of the compound (evaluation path s corresponds in Figure 9 to the z- or $\sigma_{3}$-directon). The stress gradient $G_{03}$ of the third principal stress ( $\sigma_{3}$ perpendicular to the surface) should not be considered. In Figure 9 the stress amplitudes (i.e. half of the stress-ranges $\Delta \sigma_{i}$ ) are plotted along the previously mentioned evaluation path $\mathrm{s}$ for an internal pressure $p_{i}=87.5 \mathrm{MPa}$ and the relevant stress gradient factors $G_{\sigma 1}$ or $G_{\sigma x}$ and $G_{\sigma 2}$ or $G_{\sigma y}$ are calculated by dividing the gradient $\left|\Delta \sigma_{\mathrm{ia}} / \Delta s\right|$ by the maximum amplitude $\sigma_{\mathrm{ia}, \max }$ at the inner surface $(\mathrm{s}=0)$.
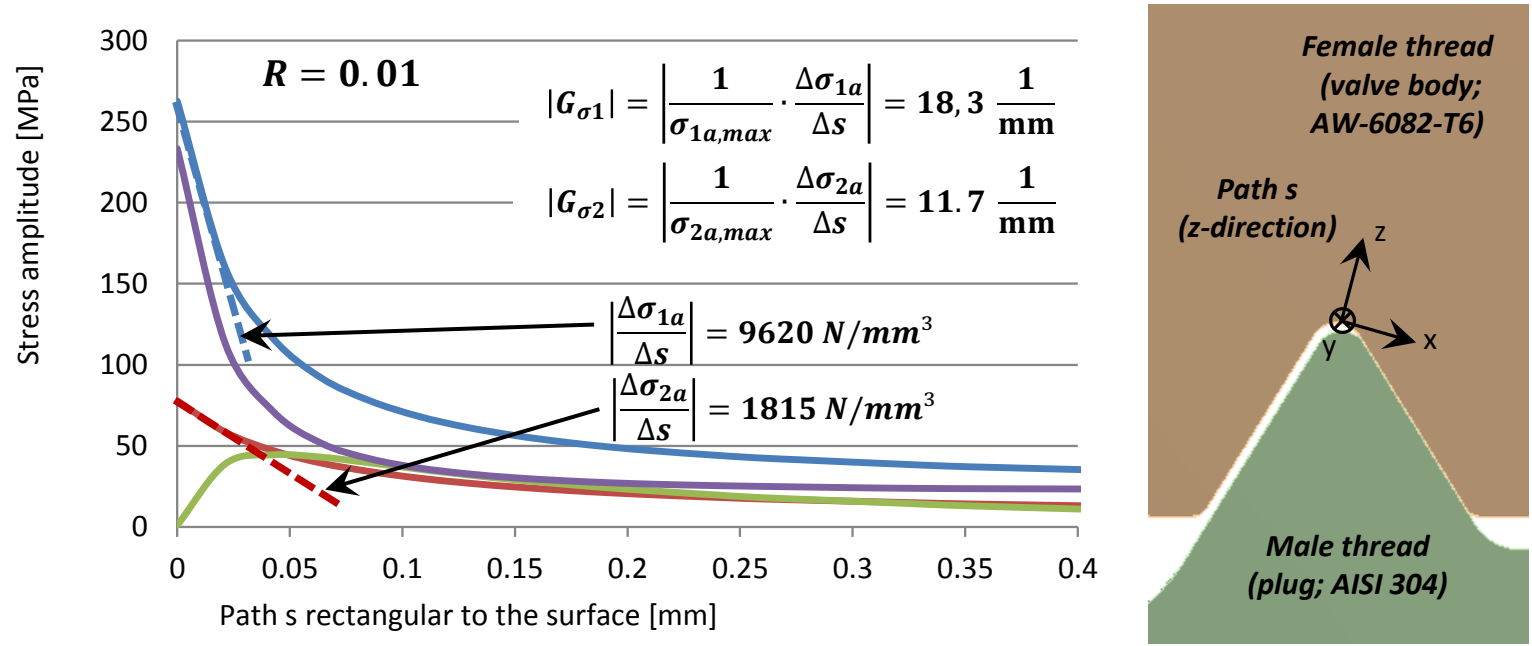

Maximum principal stress (x-direction)
Minimum principal stress (z-direction)

Middle principal stress (y-direction) Equivalent stress (Von-Mises)

Figure 9: Linear-elastic normal stress amplitudes in the first female thread and the derived stress gradients $G_{\sigma i}$

The calculation is now detailed in Table 3.

\begin{tabular}{|c|c|c|}
\hline $\begin{array}{l}\text { Principal stresses for cyclic pressure load } \\
\left(p_{\min }=0.875 \mathrm{MPa} ; p_{\max }=\right. \\
87.5 \mathrm{MPa} ; R=0.01 ; \\
\text { see Table } 2)\end{array}$ & $\begin{array}{c}\sigma_{x \max }=525 \mathrm{MPa} \\
\sigma_{y \max }=156 \mathrm{MPa} \\
\sigma_{z \max }=2 \mathrm{MPa}\end{array}$ & $\begin{aligned} \sigma_{x \min } & =5 M P a \\
\sigma_{y \min } & =2 M P a \\
\sigma_{z \min } & =0 M P a\end{aligned}$ \\
\hline $\begin{array}{l}\text { Principal stress amplitudes } \sigma_{a i} \text { and mean } \\
\text { stresses } \sigma_{m i} \text { at the investigated point for } \\
\mathrm{i}=1,2,3 \\
\text { [Chapter 4.1.1.3] }\end{array}$ & $\begin{array}{c}\sigma_{a x}=260 \mathrm{MPa} \\
\sigma_{a y}=77 \mathrm{MPa} \\
\sigma_{a z}=1 \mathrm{MPa}\end{array}$ & $\begin{array}{c}\sigma_{m x}=265(R=0.01) \\
\sigma_{m y}=79(R=0.01) \\
\sigma_{m z}=1(R=0.01)\end{array}$ \\
\hline $\begin{array}{l}\text { Material dependent constant } K_{f} \\
\text { [Chapter 4.3.1] }\end{array}$ & \multicolumn{2}{|c|}{2} \\
\hline Roughness factor $K_{R, \sigma}$ & \multicolumn{2}{|c|}{0,87} \\
\hline
\end{tabular}




\begin{tabular}{|c|c|}
\hline $\begin{array}{l}\left.\text { (surface roughness } R_{z}=6.3 \mu \mathrm{m}\right) \\
\text { [Chapter 4.3.3] }\end{array}$ & \\
\hline $\begin{array}{l}\text { Safety factor } j_{\text {ges }} \\
\text { [Chapter 4.5] }\end{array}$ & 1 \\
\hline $\begin{array}{l}\text { Allowable stress amplitude at the fatigue } \\
\text { limit } \\
\left(R_{m}: \text { ultimate tensile strength) } f_{w, \sigma} \cdot R_{m}\right. \\
\text { [Chapter 4.2.2] }\end{array}$ & $109\left(f_{w, \sigma}=0,3 ; R_{m}=364 \mathrm{MPa}\right)$ \\
\hline $\begin{array}{l}\text { Mean stress factor } K_{A K, \sigma i} \\
\text { with } M_{\sigma, A l}=0.32 \text { (mean stress } \\
\text { susceptibility) } \\
\text { [Chapter } 4.4 .2 \text {; Overload-case F3 } \\
\left(\sigma_{\min }=\text { const.)] }\right.\end{array}$ & $\begin{array}{c}K_{A K, \sigma}=\frac{\frac{1+M_{\sigma, A l} / 3}{1+M_{\sigma, A l}}-\frac{M_{\sigma, A l}}{3} \cdot s_{\min }}{1+M_{\sigma, A l}} \\
K_{A K, \sigma x}=0.75\left(s_{\min }=0.03\right) \\
K_{A K, \sigma y}=0.75\left(s_{\min }=0.01\right) \\
K_{A K, \sigma z}=0.75\left(s_{\min }=0\right)\end{array}$ \\
\hline $\begin{array}{l}\text { Endurance strength factor } K_{B K, \sigma} \text { (Fatigue } \\
\text { limit } N_{D}=10^{6} \text { cycles; } N=31,000 \text { cycles } \\
\text { (Inclination of the fatigue curve } \mathrm{k}=5 \text { ) } \\
\text { [Chapter } 4.4 .3 \text { ] }\end{array}$ & $K_{B K, \sigma x, y, z}=\left(\frac{N_{D}}{N}\right)^{\frac{1}{k}}=2$ \\
\hline $\begin{array}{l}\text { Stress gradient } G_{\sigma i} \text { and notch sensitivity } \\
\text { factor for } \mathrm{i}=1,2 n_{\sigma i}=f\left(G_{\sigma i}\right) \\
\text { [Chapter 4.3.2] }\end{array}$ & $\begin{array}{c}\left|G_{\sigma x}\right|=18.3 \mathrm{~mm}^{-1} n_{\sigma x}=1,7 \\
\left|G_{\sigma y}\right|=11.7 n_{\sigma y}=1,6 \\
\left(n_{\sigma z}=1\right)\end{array}$ \\
\hline $\begin{array}{l}\text { Cyclic load factors } a_{B K, \sigma_{i}} \\
\text { [Chapter 4.6.3.1] }\end{array}$ & $\begin{array}{c}a_{B K, \sigma_{x}}=100 \% \\
a_{B K, \sigma_{y}}=31 \% \\
a_{B K, \sigma_{z}}=0 \% \\
\end{array}$ \\
\hline \multicolumn{2}{|c|}{ Total cyclic load factor (Von-Mises theory) [Chapter 4.6.3.2] } \\
\hline \multicolumn{2}{|c|}{$=\sqrt{\frac{1}{2}}\left[\left(a_{B K, \sigma_{x}}-a_{B K, \sigma_{y}}\right)^{2}+\left(a_{B K, \sigma_{y}}-a_{B K, \sigma_{z}}\right)^{2}+\left(a_{B K, \sigma_{z}}-a_{B K, \sigma_{x}}\right)^{2}\right]=89 \%$} \\
\hline \multicolumn{2}{|c|}{$\begin{array}{l}\text { For an internal pressure } p_{i}=0.875-87.5 \mathrm{MPa}(\mathrm{R}=0.01) \text {, cracks will occur after } 31,000 \text { cycles at } \\
\text { first principal load factor } a_{B K, \sigma_{X}}=100 \% \text { in the root of the critical first thread }\end{array}$} \\
\hline
\end{tabular}

Table 3 shows a crack initiation after 31,000 cycles at the root of the first female aluminium thread.

\subsection{Calculated (NON-Linear FEM) LOAd Distribution fOR CYCLIC PRESSURE lOAding AFTER AUTOFRETTAGE WITH 300 MPA}

The roots of the first threads show high stress concentrations, while the effect of single static overloading during previous autofrettage, i.e. the residual compressive stresses due to the static overloading, are included.

The three important load steps (autofrettage pressure (LS1), complete relief (LS2) and maximum operating pressure (LS3)) were simulated in a non-linear FE-simulation, including the pressure forces of the plugged ends. Table 4 illustrates the stress ranges for load step (LS) 2 to LS3 (according to Figure 2) after autofrettage (LS1) with a pressure of $300 \mathrm{MPa}$. The static overloading with plastic yielding leads to considerable compressive stresses in the first three threads especially for the most important $\mathrm{x}$ - $\left(\right.$ or $\left.\sigma_{1}\right)$ direction. 


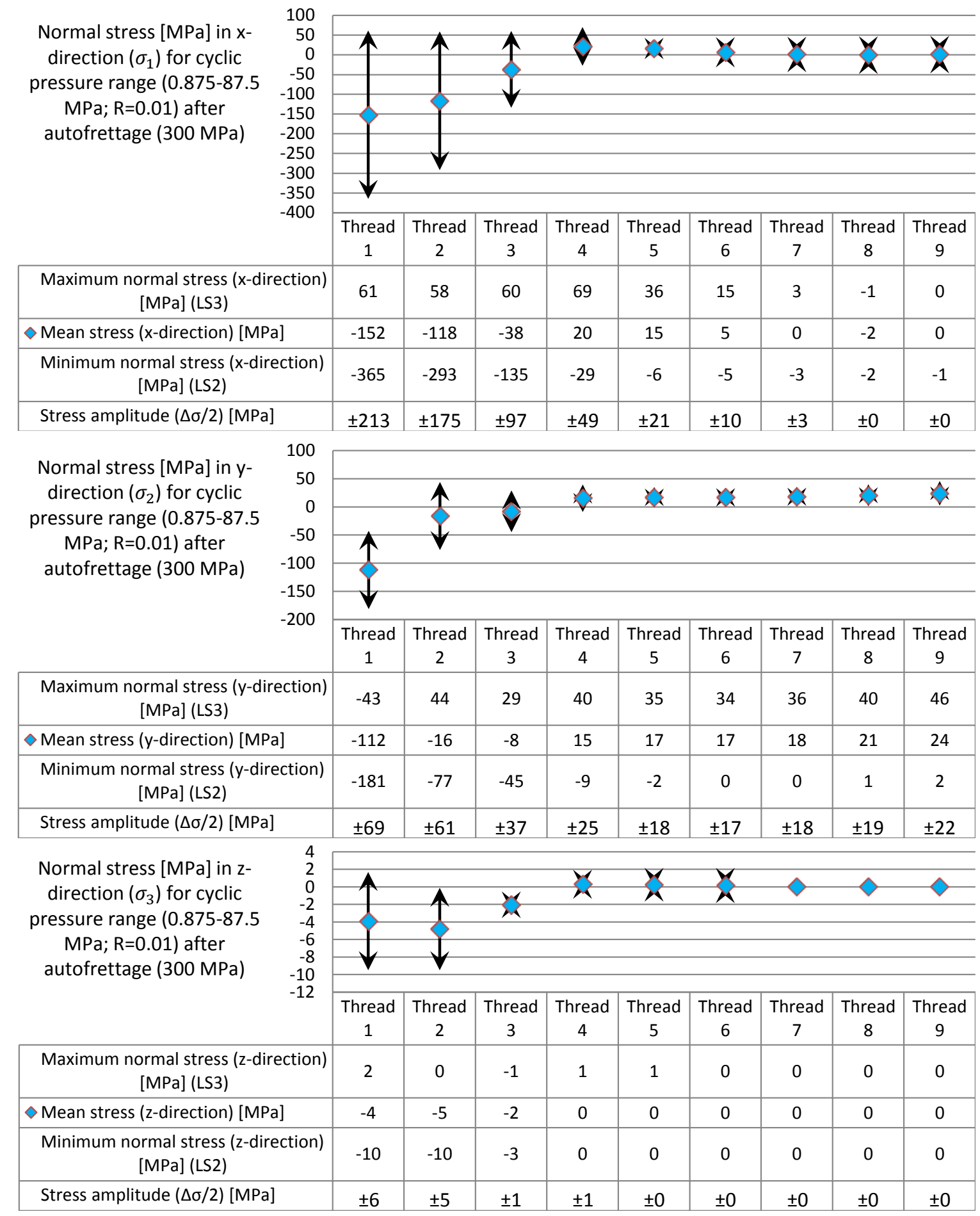

Table 4: Calculated (NL-FEM) normal stress ranges in the root of the aluminium threads including the effect of autofrettage with $300 \mathrm{MPa}$ 


\subsection{FAtigue ASSESSMENT ACCORDING TO FKM GUIDELINE FOR CYCLIC LOADING AFTER AUTOFRETTAGE WITH 300 MPA}

As already shown in the previous paragraph the autofrettage (LS1) and the subsequent pressure relief (LS2) have to be calculated with the Non-Linear Finite Element Method (NL-FEM) in order to correctly estimate the residual stresses. But the assessment procedure according to FKM guideline requires linear elastic stress ranges (or amplitudes) based on real mean stresses. It will be shown later (Figure 10) that only LS1 and LS2 lead to plastic yielding (non-linear behaviour), but not the subsequent cyclic loading of LS3, LS4, LS5, LS6,...... Hence we simply take the non-linearly calculated stresses of LS2 to get the mean values and add the elastic stress ranges based on Table 2 and Figure 9 for an almost swelling pressure from 0.875 to $87.5 \mathrm{MPa}(\mathrm{R}=0.01)$. If we now repeat the fatigue calculation of chapter 3.4 for the first carrying female thread, the number of cycles prior to failure is highly increased (Table 5) due to the now mean compressive stresses

\begin{tabular}{|c|c|c|}
\hline $\begin{array}{l}\text { Principal stresses after load step } 2 \text { (LS2) as } \\
\text { result of the non-linear finite FE-simulation } \\
\text { (Table 4) (autofrettage pressure: } 300 \mathrm{MPa} \text { ) } \\
\text { corrected by the minimum elastic stresses } \\
\text { at minimum pressure of } 0.875 \mathrm{MPa}\end{array}$ & \multicolumn{2}{|c|}{$\begin{array}{c}\sigma_{x}=-365 \mathrm{MPa}+0.01 \cdot 525 \mathrm{MPa}=-360 \mathrm{MPa} \\
\sigma_{y}=-181 \mathrm{MPa}+0.01 \cdot 156 \mathrm{MPa}=-179 \mathrm{MPa} \\
\sigma_{z}=-10 \mathrm{MPa}+0.01 \cdot 2 \mathrm{MPa}=-9 \mathrm{MPa}\end{array}$} \\
\hline $\begin{array}{l}\text { Principal elastic stress ranges for the } \\
\text { subsequent cyclic pressure loading } \\
\left(p_{\min }=0.875 M P a ; p_{\max }=\right. \\
87.5 M P a ; R=0.01),(\text { Table } 2)\end{array}$ & \multicolumn{2}{|c|}{$\begin{array}{c}\Delta \sigma_{x}=525 \mathrm{MPa}-5 \mathrm{MPa}=520 \mathrm{MPa} \\
\Delta \sigma_{y}=156 \mathrm{MPa}-2 \mathrm{MPa}=154 \mathrm{MPa} \\
\Delta \sigma_{z}=2 \mathrm{MPa}\end{array}$} \\
\hline $\begin{array}{l}\text { Principal stress amplitudes for cyclic } \\
\text { pressure load }\left(p_{\min }=0.875 \mathrm{MPa} ; p_{\max }=\right. \\
87.5 \mathrm{MPa} ; R=0.01) \\
\text { Note: in Figure } 9 \text { the amplitudes are } \\
\text { shown. }\end{array}$ & $\begin{array}{c}\sigma_{a x}=260 \mathrm{MPa} \\
\sigma_{a y}=77 \mathrm{MPa} \\
\sigma_{a z}=1 \mathrm{MPa}\end{array}$ & $\begin{array}{c}\sigma_{m x}=-100(R=-6) \\
\sigma_{m y}=-102(R=4) \\
\sigma_{m z}=-8(R=0)\end{array}$ \\
\hline $\begin{array}{l}\text { Material dependent constant } K_{f} \\
\text { [Chapter 4.3.1] }\end{array}$ & \multicolumn{2}{|c|}{2} \\
\hline $\begin{array}{l}\text { Roughness factor } K_{R, \sigma} \\
\left(\text { surface roughness } R_{z}=6.3 \mu \mathrm{m}\right) \\
\text { [Chapter 4.3.3] }\end{array}$ & \multicolumn{2}{|c|}{0.865} \\
\hline $\begin{array}{l}\text { Safety factor } j_{\text {ges }} \\
\text { [Chapter } 4.5]\end{array}$ & \multicolumn{2}{|c|}{1} \\
\hline $\begin{array}{l}\text { Allowable stress amplitude at the fatigue } \\
\text { limit } \\
\left(R_{m}: \text { ultimate tensile strength) } f_{w, \sigma} \cdot R_{m}\right. \\
\text { [Chapter 4.2.2] }\end{array}$ & \multicolumn{2}{|c|}{$109\left(f_{w, \sigma}=0,3 ; R_{m}=364\right)$} \\
\hline $\begin{array}{l}\text { Mean stress factor } K_{A K, \sigma i} \\
\text { with } M_{\sigma, A l}=0.324 \text { (mean stress } \\
\text { susceptibility) } \\
\text { [Chapter } 4.4 .2 ; \text { overload-case: F3 } \\
\left(\sigma_{\min }=\text { const.) }\right.\end{array}$ & \multicolumn{2}{|c|}{$\begin{array}{c}K_{A K, \sigma}=\frac{1-M_{\sigma, A l} \cdot s_{\min }}{1+M_{\sigma, A l}}=1,3 \\
K_{A K, \sigma x}=1.3\left(s_{\min }=-2\right) \\
K_{A K, \sigma y}=1\left(s_{\min }=-1\right) \\
K_{A K, \sigma z}=0.8\left(s_{\min }=0\right)\end{array}$} \\
\hline $\begin{array}{l}\text { Endurance strength factor } K_{B K, \sigma} \text { (Fatigue } \\
\text { limit } N_{D}=10^{6} \text { cycles; } N=420,000 \text { cycles } \\
\text { (Inclination of the fatigue curve } \mathrm{k}=5 \text { ) } \\
\text { [Chapter } 4.4 .3 \text { ] }\end{array}$ & \multicolumn{2}{|c|}{$K_{B K, \sigma x, y, z}=\left(\frac{N_{D}}{N}\right)^{\frac{1}{k}}=1.2$} \\
\hline $\begin{array}{l}\text { Stress gradient } G_{\sigma i} \text { and notch sensitivity } \\
\text { factor for } \mathrm{i}=1,2 n_{\sigma i}=f\left(G_{\sigma i}\right)\end{array}$ & $\begin{array}{l}\left|G_{\sigma x}\right|=18 \\
\left|G_{\sigma y}\right|=11\end{array}$ & $\begin{array}{ll}m^{-1} & n_{\sigma x}=1.7 \\
m^{-1} & n_{\sigma y}=1.6\end{array}$ \\
\hline
\end{tabular}




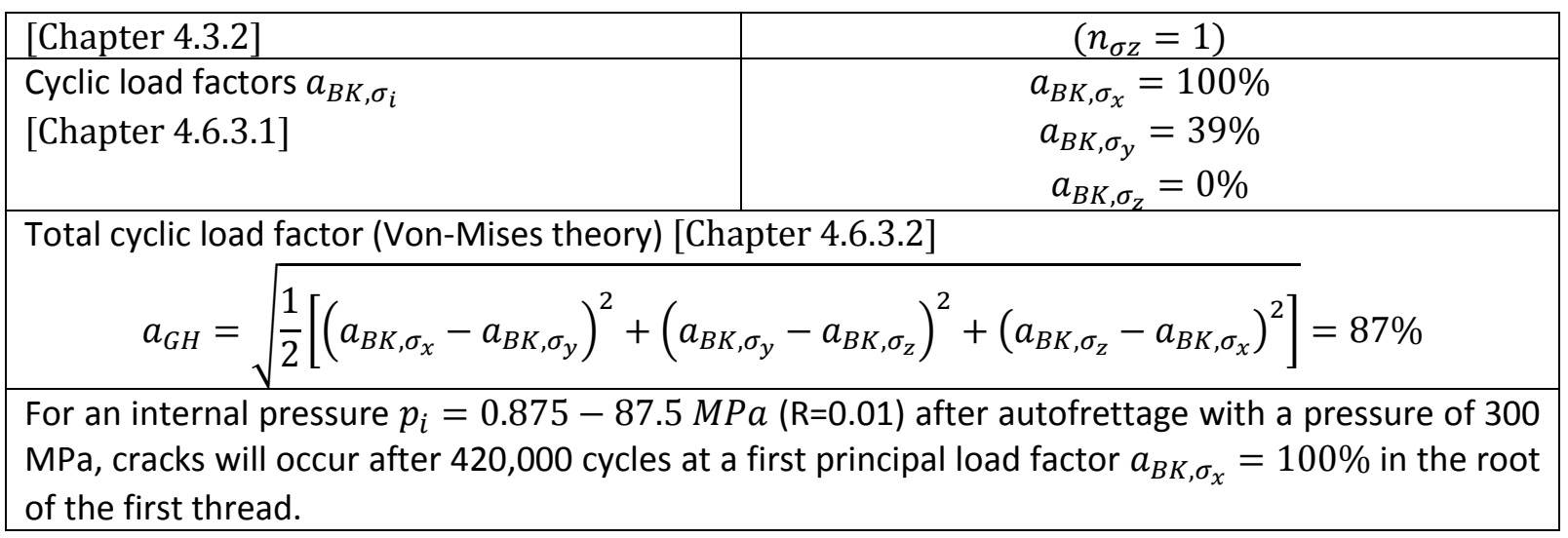

Table 5: Calculation sequence according to FKM guideline for $\mathrm{p}=0.875-87.5 \mathrm{MPa}(\mathrm{R}=0.01)$ after autofrettage with 300 $\mathrm{MPa}$

Thus the residual stresses lead to an improved fatigue resistance, which can be understood with the above mentioned HAIGH-diagram.

The normal stress amplitude in $x$-direction of the first critical thread root is reduced by about $19 \%$ (Table 6) from the initial normal stress amplitude without autofrettage from $265 \pm 260 \mathrm{MPa}$ (see Table 2 and Table 6) to $-152 \pm 211 \mathrm{MPa}$. However, if we take a closer look at the load distribution at the following aluminium thread roots, the second thread root shows an increased stress range ($118 \pm 175 \mathrm{MPa}$ ) compared to the situation without autofrettage $(113 \pm 110 \mathrm{MPa})$. The yielding of the first root increases the loading of the second one.

\begin{tabular}{|c|c|c|c|}
\hline \multirow{6}{*}{$\begin{array}{l}\text { Normal stress }[\mathrm{MPa} \text { ] in } \mathrm{x}- \\
\text { direction }\left(\sigma_{1}\right) \text { for cyclic } \\
\text { pressure range }(0.875-87.5 \\
\mathrm{MPa} \text {, } \mathrm{R}=0.01)\end{array}$} & \multirow{6}{*}{$\begin{array}{r}600 \\
500 \\
400 \\
300 \\
200 \\
100 \\
0 \\
-100 \\
-200 \\
-300 \\
-400\end{array}$} & & \\
\hline & & \multicolumn{2}{|l|}{ 个 } \\
\hline & & \multicolumn{2}{|c|}{ Amplitude reduction of $19 \%$} \\
\hline & & \multirow{2}{*}{\multicolumn{2}{|c|}{$\downarrow$}} \\
\hline & & & \\
\hline & & $\begin{array}{l}\text { Cyclic stress range operating load } \\
\text { without autofrettage as result of a } \\
\text { linear-elastic FE-simulation }\end{array}$ & $\begin{array}{c}\text { Cyclic stress range operating load after } \\
\text { autofrettage ( } 300 \mathrm{MPa} \text { ) as a result of } \\
\text { the non-linear } \mathrm{FE} \text {-simulation }\end{array}$ \\
\hline \multicolumn{2}{|c|}{$\begin{array}{c}\text { Maximum normal stress (x-direction) } \\
{[\mathrm{MPa}] \text { (first thread) }}\end{array}$} & 525 & 61 \\
\hline \multicolumn{2}{|c|}{$\begin{array}{l}\diamond \text { Mean stress (x-direction) [MPa] (first } \\
\text { thread) }\end{array}$} & 265 & -152 \\
\hline \multicolumn{2}{|c|}{$\begin{array}{c}\text { Minimum normal stress (x-direction) } \\
{[\mathrm{MPa}] \text { (first thread) }}\end{array}$} & 5 & -360 \\
\hline \multicolumn{2}{|l|}{ Stress amplitude $(\Delta \sigma / 2)[\mathrm{MPa}]$} & \pm 260 & \pm 211 \\
\hline
\end{tabular}

Table 6: Change of first principal stresses (x-direction) at the root of the first thread due to autofrettage

Figure 10 shows the stress-strain path of the normal stress in $\mathrm{x}$-direction at the first aluminium thread flank for the three load steps: autofrettage with $300 \mathrm{MPa}$ (LS1), complete pressure removal (LS2) followed by the maximum operating pressure of $87.5 \mathrm{MPa}$ (LS3). 


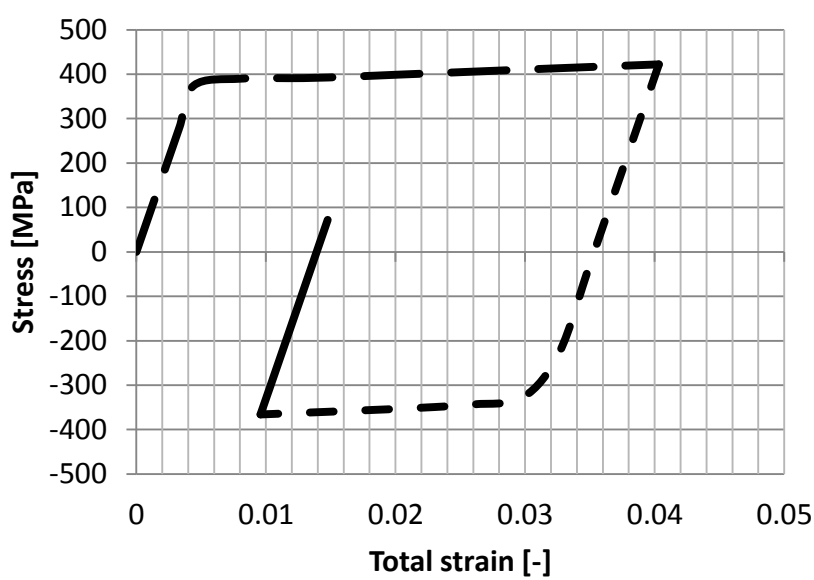

Stress-strain behaviour normal to the local x-direction for load step (LS)1 (autofrettage pressure; $300 \mathrm{MPa}$ )

- Stress-strain behaviour normal to the local x-direction load step (LS)2 (complete pressure removal; $0 \mathrm{MPa}$ )

Stress-strain behaviour normal to the local x-direction load step (LS)3 (maximum operating pressure; $87.5 \mathrm{MPa}$ )

Figure 10: Stress-strain path normal to the local x-direction for the three load steps LS1-LS3

One clearly sees that only LS1 and LS2 are non-linear while the subsequent steps (LS2 to LS3 and all following LS) lead only to linear variations. The bending and plastic deformation of the first flank reduces the stresses there while the subsequent flanks are higher charged. Hence the axial stress gradient is decreased and the distribution is equalized due to plastic deformation. Figure 11 clearly shows an axial yielding of max. $4.3 \mu \mathrm{m}$ for the first flank at LS2 and less than $2 \mu \mathrm{m}$ for the second flank.

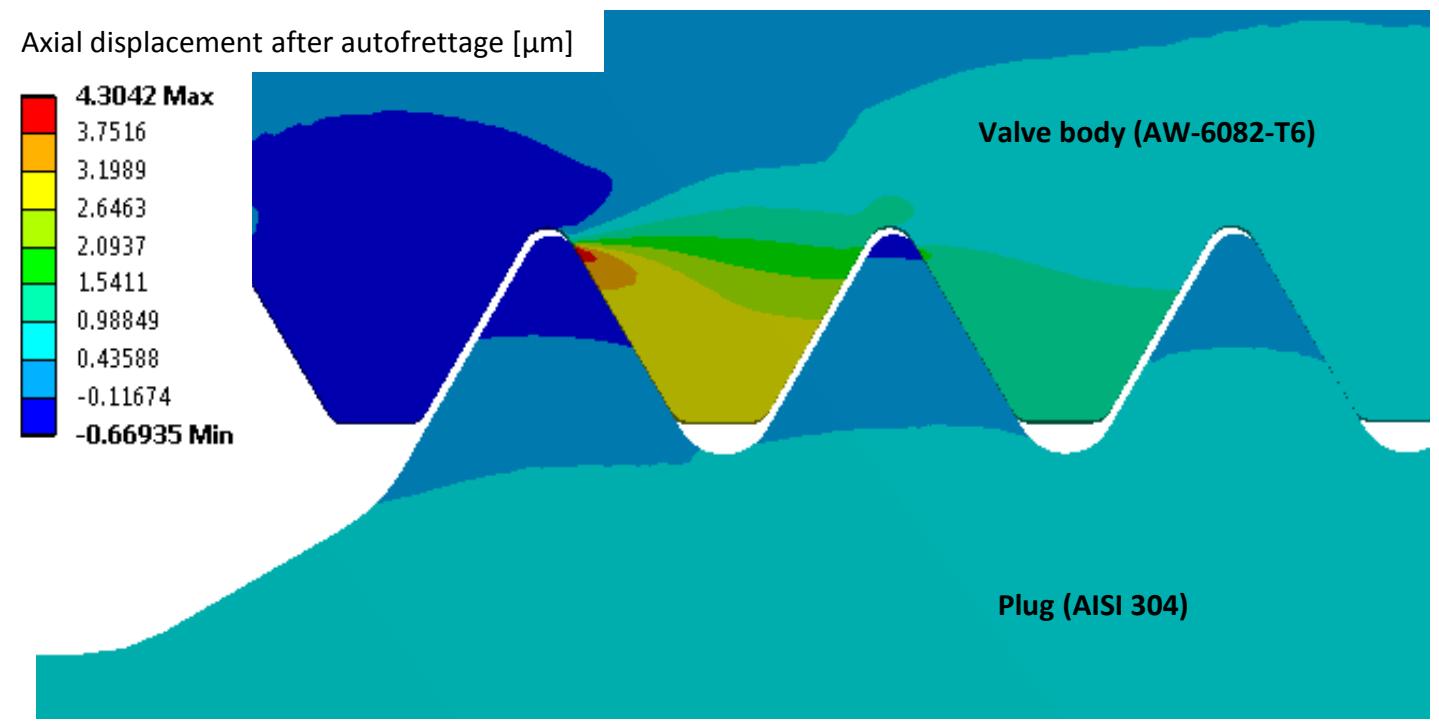

Figure 11: Axial displacement after load step 2 (complete load removal)

This stress redistribution should be considered and leads to the following reduced stress ranges after autofrettage: $\sigma_{a x}=211 \mathrm{MPa} ; \sigma_{a y}=68 \mathrm{MPa} ; \sigma_{a z}=6 \mathrm{MPa}$ Considering this effect in the FKM fatigue assessment leads to more than 1 million cycles under the assumption that all other coefficients remain unchanged.

Summing up we see, that autofrettage (or an equivalent torque-up with controlled plastic yielding) leads to compressive mean stresses and reduced amplitudes at the hot spot resulting in a highly increased fatigue lifetime. 


\subsection{EXPERIMENTAL RESULTS WITH MICROSECTION}

In order to prove to above detailed design calculations a series of tests were done first without autofrettage and almost swelling pressure from 0.875 to $87.5 \mathrm{MPa}(R=0.01)$. Table 7 shows the opened specimens after different given number of cycles with a picture and a microsection.

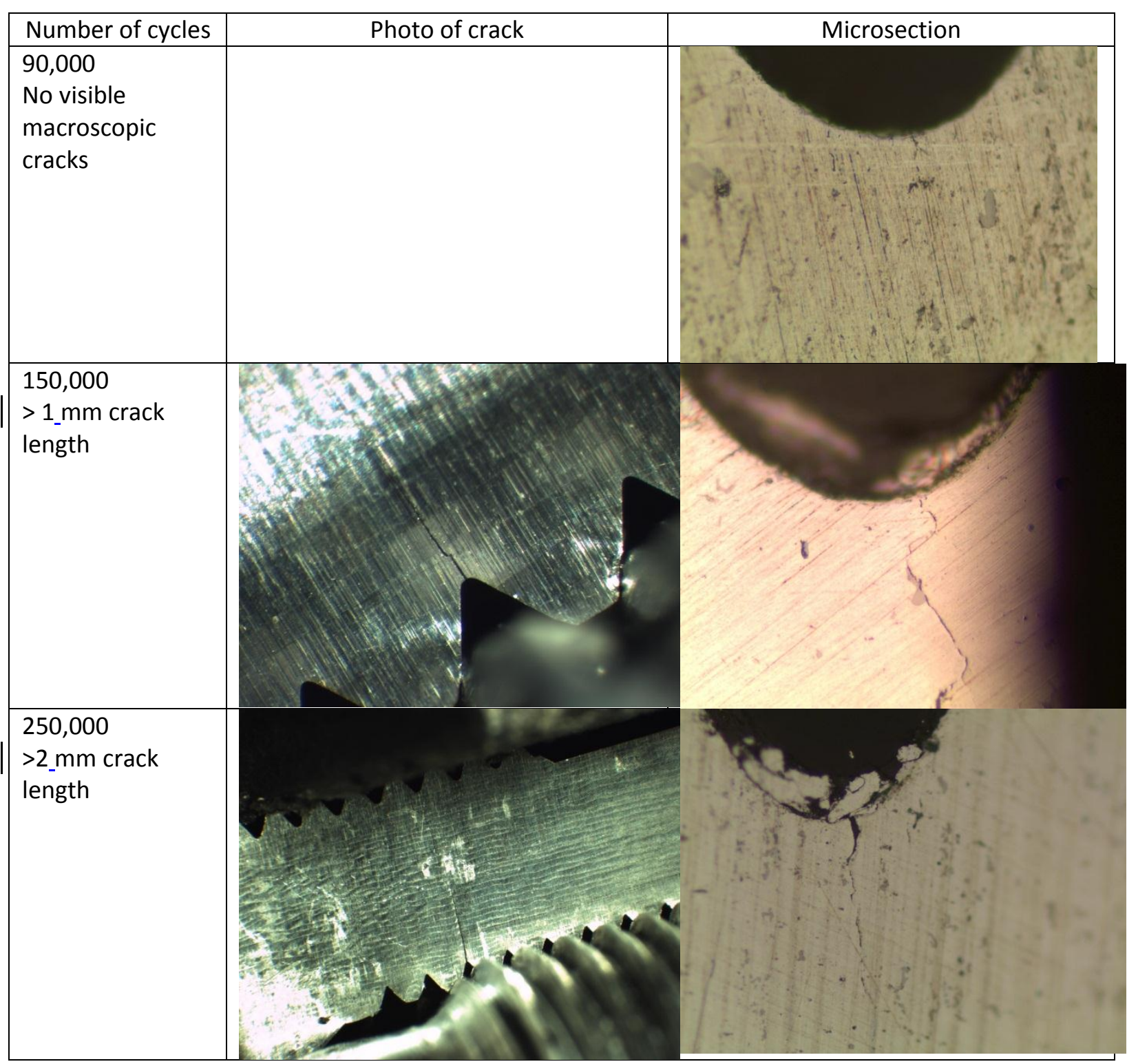

Table 7: Photos and microsections of the opened specimens without autofrettage after cyclic testing

Figure 12 now shows a specimen with autofrettage of $300 \mathrm{MPa}$ and subsequent cyclic testing with our usual swelling pressure from 0.875 to $87.5 \mathrm{MPa}(\mathrm{R}=0.01)$ after 1 million cycles: no cracks are visible. 


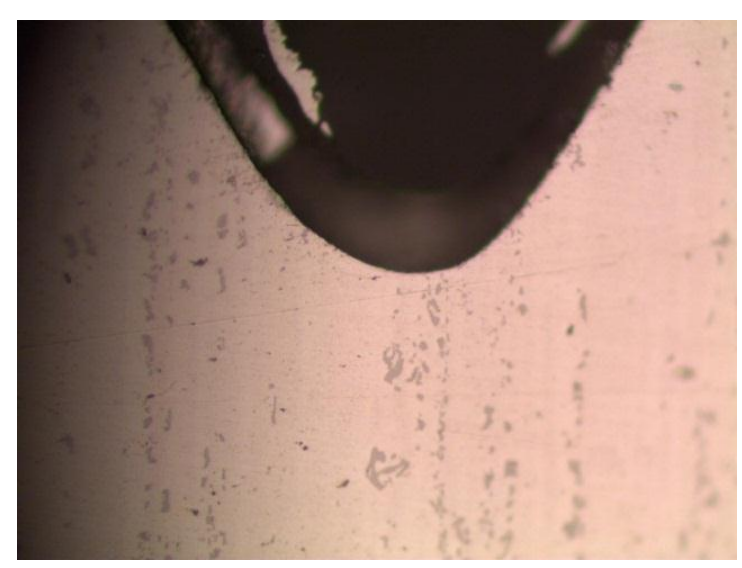

Figure 12: Microsection of a specimen after autofrettage and 1 million pressure cycles without crack

\section{Sensitivity analysis}

In the subsequent chapters different material combination and their impact on the stress distribution in the thread including the change in stress amplitudes for the critical point are investigated. Until now (see par. 3.1) the plug (male thread) was SS 304; now the analysis is done with SS 304L and additionally aluminium for the plug.

\subsection{Male thread of Stainless Steel SS 304L}

For the plug or screw material stainless steel AISI $304 \mathrm{~L}$ was now chosen, which has even lower yield strength than our aluminium (Boller et al. [15]). Figure 13 shows the measured static stress-strain behaviour for all used materials.

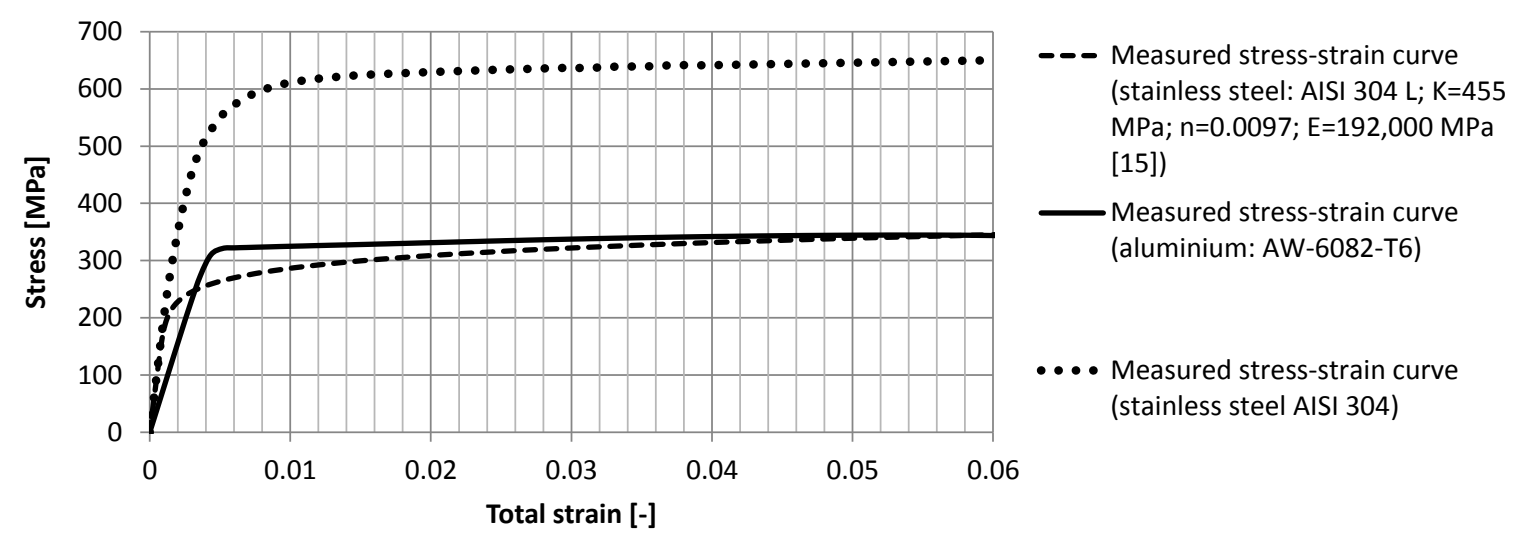

Figure 13: Statically measured stress-strain curves for stainless steel AISI 304 L, 304 and aluminium AW-6082-T6

The simulation for the second load step (LS2, complete load removal) shows of course after autofrettage with $300 \mathrm{MPa}$ larger zones of plastic axial-straining at the two first male thread flanks compared to the previous plug of SS304 (Figure 11). 


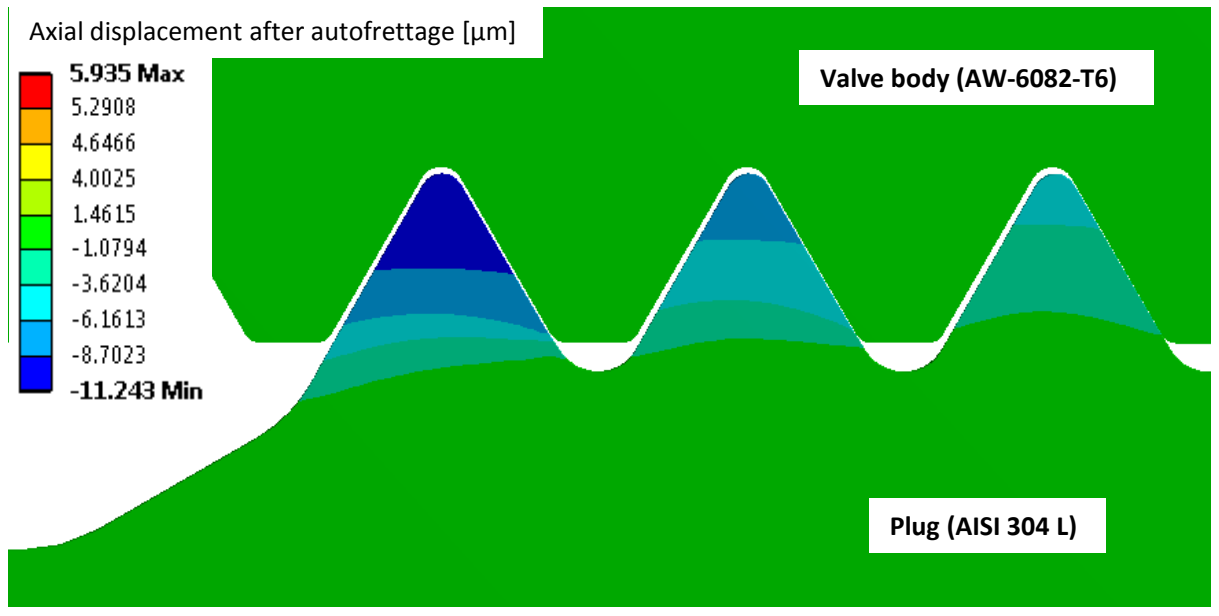

Figure 14: Total plastic strain at load step 2 (complete removal of autofrettage pressure) for stainless steel plug SS304L

In the normal stress ranges of the first thread flanks of the aluminium compound are listed in Table 8. A comparison with Table 4 quickly reveals that now the second thread flank (now $-155 \pm 199 \mathrm{MPa}$ ) and no longer the first (before $-152 \pm 213 \mathrm{MPa}$ ) becomes the hot spot with approximately the same charging. 
Normal stress [MPa] in $\mathrm{x}$ direction $\left(\sigma_{1}\right)$ for cyclic pressure range (0.875-87.5

$\mathrm{MPa} ; \mathrm{R}=0.01$ ) after autofrettage (300 MPa) (softer screw material AISI 304L)
300

200

100

0

$-100$

$-200$

$-300$

$-400$

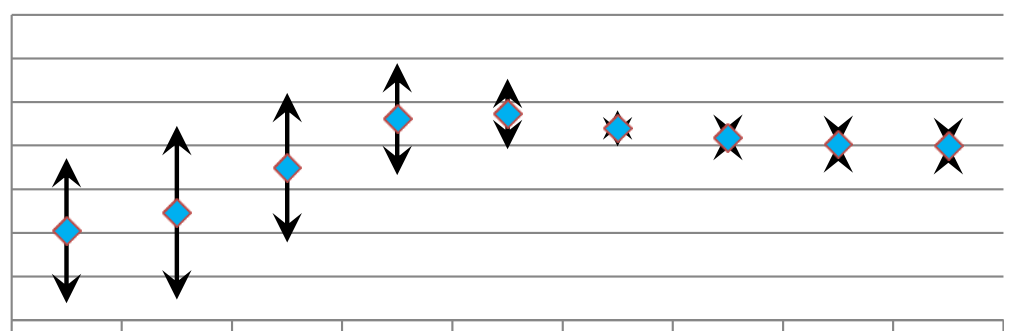

\begin{tabular}{|c|c|c|c|c|c|c|c|c|c|}
\hline \multirow[b]{2}{*}{$\begin{array}{ll}-400 \\
-2+2\end{array}$} & \multirow[b]{2}{*}{$\begin{array}{c}\text { Thread } \\
1\end{array}$} & \multirow[b]{2}{*}{$\begin{array}{c}\text { Thread } \\
2\end{array}$} & \multirow[b]{2}{*}{\begin{tabular}{|c} 
Thread \\
3
\end{tabular}} & \multirow[b]{2}{*}{$\begin{array}{c}\text { Thread } \\
4\end{array}$} & \multirow[b]{2}{*}{$\begin{array}{c}\text { Thread } \\
5\end{array}$} & \\
\hline & & & & & & $\begin{array}{l}\text { Thread } \\
6\end{array}$ & $\begin{array}{c}\text { Thread } \\
7\end{array}$ & $\begin{array}{c}\text { Thread } \\
8\end{array}$ & $\begin{array}{c}\text { Thread } \\
9\end{array}$ \\
\hline $\begin{array}{l}\text { Maximum normal stress (x-direction) } \\
{[\mathrm{MPa}]}\end{array}$ & -30 & 44 & 120 & 188 & 152 & 80 & 33 & 5 & 0 \\
\hline Mean stress (x-direction) [MPa] & -196 & -155 & -52 & 60 & 71 & 39 & 18 & 3 & -2 \\
\hline $\begin{array}{l}\text { Minimum normal stress (x-direction) } \\
{[\mathrm{MPa}]}\end{array}$ & -362 & -354 & -223 & -69 & -10 & -3 & 3 & 1 & -4 \\
\hline Stress amplitude $(\Delta \sigma / 2)[\mathrm{MPa}]$ & \pm 166 & \pm 199 & \pm 171 & \pm 128 & \pm 81 & \pm 41 & \pm 15 & \pm 2 & \pm 2 \\
\hline
\end{tabular}

Normal stress [MPa] in y- 100 direction $\left(\sigma_{2}\right)$ for cyclic pressure range (0.875-87.5 $\mathrm{MPa} ; \mathrm{R}=0.01$ ) after autofrettage (300 MPa)

(softer screw material AISI 304L)

\begin{tabular}{|c|c|c|c|c|c|c|c|c|c|}
\hline & 1 & 2 & 3 & 4 & 5 & 6 & 1 & 8 & 9 \\
\hline $\begin{array}{l}\text { Maximum normal stress (y-direction) } \\
{[\mathrm{MPa}]}\end{array}$ & -72 & 32 & 51 & 76 & 73 & 58 & 51 & 50 & 56 \\
\hline$\Delta$ Mean stress (y-direction) [MPa] & -124 & -33 & -8 & 26 & 35 & 29 & 27 & 26 & 29 \\
\hline $\begin{array}{l}\text { Minimum normal stress (y-direction) } \\
\text { [MPa] }\end{array}$ & -175 & -98 & -68 & -23 & -3 & 0 & 2 & 2 & 2 \\
\hline Stress amplitude $(\Delta \sigma / 2)[\mathrm{MPa}]$ & \pm 51 & \pm 65 & \pm 60 & \pm 49 & \pm 38 & \pm 29 & \pm 24 & \pm 24 & \pm 27 \\
\hline
\end{tabular}

Normal stress [MPa] in zdirection $\left(\sigma_{3}\right)$ for cyclic pressure range $(0.875-87.5$

$\mathrm{MPa} ; \mathrm{R}=0.01)$ after autofrettage (300 MPa) (softer screw material AISI

\begin{tabular}{|c|} 
(softer screw material AISI \\
304L)
\end{tabular}

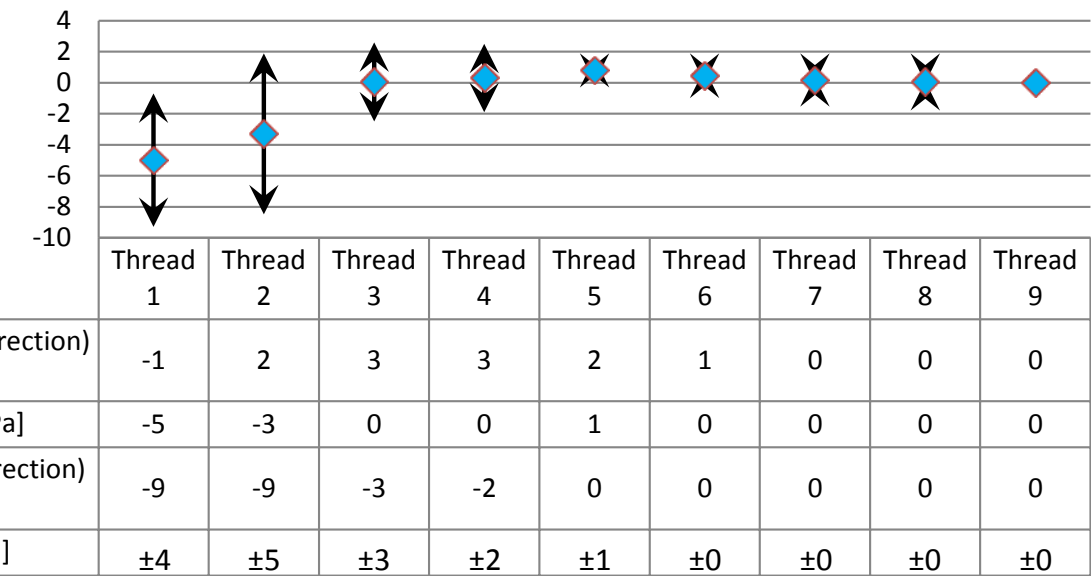

Table 8: Calculated (NL-FEM) normal stress in the root of the aluminium thread flanks including autofrettage with 300 MPa for a SS 304L plug)

\subsection{ALUMINIUM SCREW}

Finally the use of aluminium for the plug is analyzed. The normal stress range distribution is illustrated in Table 9. Analogously to the soft SS 304L screw, there is a large zone of plastic straining in the first male and the female thread flanks (Figure 15). 


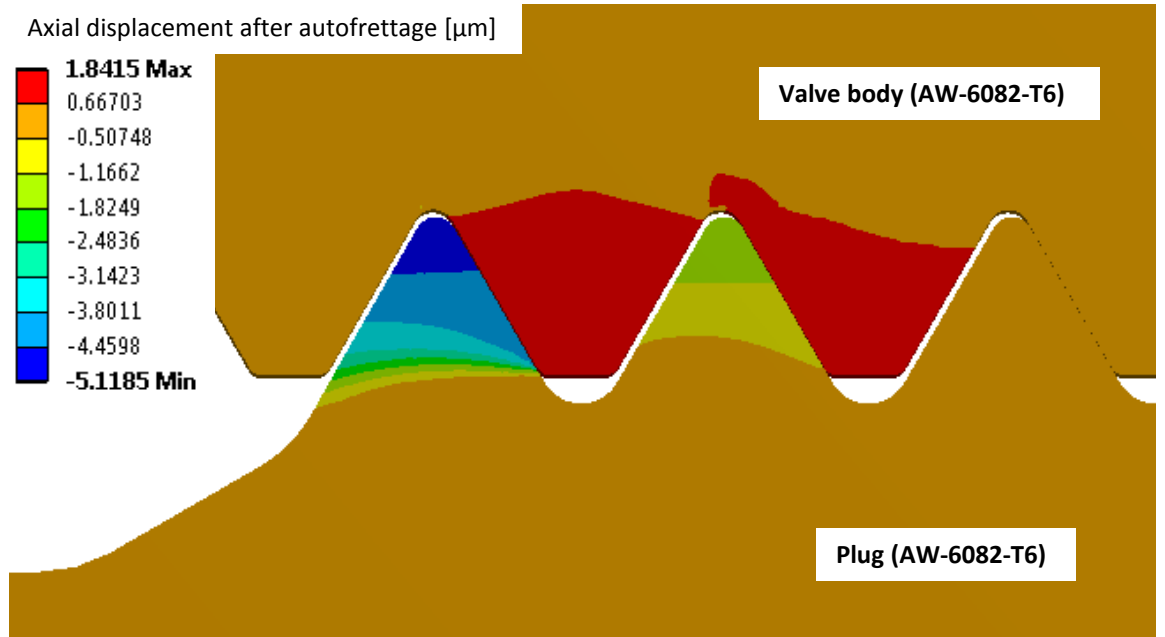

Figure 15: Total plastic strain at load step 2 (complete removal of autofrettage pressure) for an aluminium plug 
Normal stress [MPa] in $\mathrm{x}$ direction $\left(\sigma_{1}\right)$ for cyclic pressure range (0.875-87.5 $\mathrm{MPa} ; \mathrm{R}=0.01)$ after autofrettage (300 MPa)

(aluminium screw AW-6082T6)

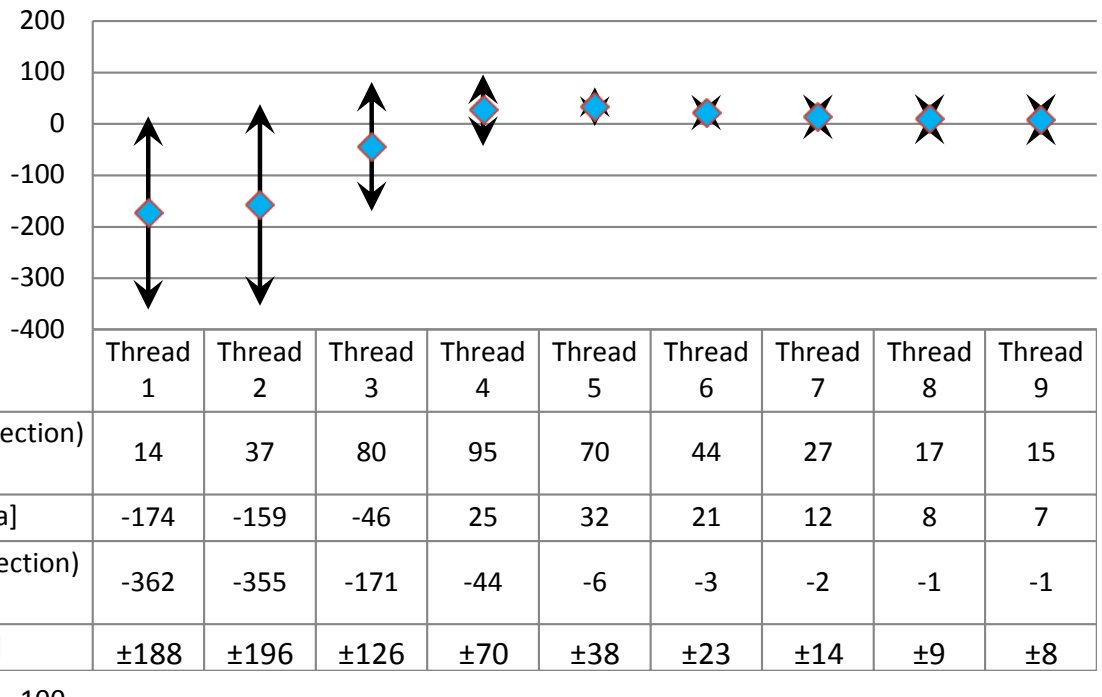

Normal stress [MPa] in ydirection $\left(\sigma_{2}\right)$ for cyclic pressure range $(0.875-87.5$ $\mathrm{MPa} ; \mathrm{R}=0.01$ ) after autofrettage (300 MPa) (aluminium screw AW-6082- - -200 T6)

\begin{tabular}{|c|c|c|c|c|c|c|c|c|c|}
\hline & 1 & 2 & 3 & 4 & 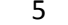 & 6 & 7 & 8 & 9 \\
\hline $\begin{array}{l}\text { Maximum normal stress (y-direction) } \\
{[\mathrm{MPa}]}\end{array}$ & -51 & 32 & 36 & 48 & 47 & 45 & 47 & 51 & 58 \\
\hline Mean stress (y-direction) [MPa] & -112 & -35 & -11 & 17 & 23 & 23 & 24 & 26 & 30 \\
\hline $\begin{array}{l}\text { Minimum normal stress (y-direction) } \\
{[\mathrm{MPa}]}\end{array}$ & -172 & -101 & -57 & -15 & -1 & 0 & 1 & 1 & 2 \\
\hline Stress amplitude $(\Delta \sigma / 2)[\mathrm{MPa}]$ & \pm 61 & \pm 66 & \pm 46 & \pm 31 & \pm 24 & \pm 23 & \pm 23 & \pm 25 & \pm 28 \\
\hline
\end{tabular}

Normal stress [MPa] in zdirection $\left(\sigma_{3}\right)$ for cyclic pressure range (0.875-87.5 $\mathrm{MPa} ; \mathrm{R}=0.01$ ) after autofrettage (300 MPa) (aluminium screw AW-6082T6)

\begin{tabular}{|c|c|c|c|c|c|c|c|c|c|}
\hline & 1 & 2 & 3 & 4 & 5 & 6 & 7 & 8 & 9 \\
\hline $\begin{array}{l}\text { Maximum normal stress (z-direction) } \\
{[\mathrm{MPa}]}\end{array}$ & 0 & 1 & -1 & 1 & 1 & 1 & 0 & 0 & 0 \\
\hline Mean stress (z-direction) [MPa] & -4 & -4 & -3 & 0 & 0 & 0 & 0 & 0 & 0 \\
\hline $\begin{array}{l}\text { Minimum normal stress (z-direction) } \\
\text { [MPa] }\end{array}$ & -9 & -9 & -6 & -1 & 0 & 0 & 0 & 0 & 0 \\
\hline Stress amplitude $(\Delta \sigma / 2)[\mathrm{MPa}]$ & \pm 5 & \pm 5 & \pm 2 & \pm 1 & \pm 0 & \pm 0 & \pm 0 & \pm 0 & \pm 0 \\
\hline
\end{tabular}

Table 9: Calculated (NL-FEM) normal stress in the root of the aluminium thread flanks including autofrettage with 300 MPa for an aluminium plug)

Also for this material combination, a comparison of Table 4 and Table 10 shows that the second thread flank $(-159 \pm 196 \mathrm{MPa})$ is after autofrettage the critical one and no longer the first one as before $(-152 \pm 213 \mathrm{MPa})$. But it should be highlighted that yielding of the plug may lead to other disadvantages when untightening the connection and later in service the plug is removed and a new functional compound is screwed in this threaded hole. This new male thread is not deformed and this fact may lead to other problems. 


\section{Conclusion}

Threaded aluminium connections in the valve body can easily become the weakest point when autofrettage is used in a common way to increase the fatigue strength of tubes and bore crossings inside the compound, i.e. when the threaded connections are discharged during autofrettage. Of cause a failure of the threaded connection during the application of the autofrettage pressure has to be checked and avoided, but a single static loading with yielding caused by the autofrettage pressure can considerably improve the fatigue-lifetime. It was shown that residual compressive stresses can be generated in the female thread and a complex stress redistribution over several thread flanks takes place. This yielding changes also the stress amplitudes though the subsequent cyclic stressstrain behaviour is linear, allowing for instance the use of the FKM guideline for fatigue assessment. The fatigue resistance was considerably improved so that the complete valve body withstands one million cycles whereas with unloaded threads only bear 150,000 cycles prior to crack initiation. This result simplifies the autofrettage process considerably and of course the same result may be achieved by any other means (i.e. tightening torque) under the condition that the pre-stressing process to generate the residual stresses in the aluminium compound can be controlled sufficiently precise.

The autofrettage pressure or any similar process must be thoroughly designed e.g. by non-linear finite element calculations. Here the simulations were checked by selective experimental cyclic testing that fully confirmed the simulations and FKM-assessment. To avoid cracking or crack initiation in this early step the plastic strain should at any point be limited by the material's fracture strain.

It has advantages if the strength of the plug or male thread during autofrettage is higher than the strength of the aluminium body. In this case yielding is limited to the latter compound with the female thread and plug with the male thread may be changed to the final functional compound for normal use and cyclic loading.

Further research should be done with other materials and their combination.

\section{References}

\begin{tabular}{|l|l|}
\hline$[1]$ & $\begin{array}{l}\text { Verordnung (EG) Nr. 79/2009 des Europäischen Parlaments und des Rates: Über die } \\
\text { Typengenehmigung von wasserstoffbetriebenen Kraftfahrzeugen und zur Änderung der } \\
\text { Richtlinie 2007/46/EG. } \\
\text { Amtsblatt der Europäischen Union, 14. Januar } 2007\end{array}$ \\
\hline$[2]$ & $\begin{array}{l}\text { M. Schön, T. Seeger, J. W. Bergmann, M. Vormwald. Autofrettage I, } \\
\text { Dauerfestigkeitssteigerung durch Autofrettage. } \\
\text { Vorhaben Nr. 478, Forschungsvereinigung Verbrennungskraftmaschinen e.V., Frankfurt } \\
\text { am Main 1993. }\end{array}$ \\
\hline
\end{tabular}




\begin{tabular}{|c|c|}
\hline [3] & $\begin{array}{l}\text { T. Seeger, S. Greuling, J. W. Bergmann. Autofrettage II, Dauerfestigkeitsteigerung durch } \\
\text { Autofrettage II. } \\
\text { Vorhaben Nr. 671, Forschungsvereinigung Verbrennungskraftmaschinen e.V., Frankfurt } \\
\text { am Main } 2001 .\end{array}$ \\
\hline [4] & $\begin{array}{l}\text { Sellen, S., Maas, S., Andreas, T., Plapper, P., Zürbes, A., Becker, D.: Design concept for an } \\
\text { aluminium valve body under high internal cyclic pressure loading based on autofrettage; } \\
\text { design rule for autofrettage pressure based on static non-linear finite element } \\
\text { simulations and experimental verification. [Under review] } \\
\text { International Journal of Pressure Vessels and Piping, Elsevier }\end{array}$ \\
\hline [5] & $\begin{array}{l}\text { Kampmann, B., Diemer, J.: Autofrettage process and autofrettage apparatus. } \\
\text { Pub. No.: US2010/0154501 A1 }\end{array}$ \\
\hline [6] & $\begin{array}{l}\text { Wang, W., Marshek, K. M.: Determination of load distribution in a threaded connector } \\
\text { with yielding threads. } \\
\text { Mech. Mach. Theory Vol. 31, No. 2, pp. 229-244, 1996, Elsevier Science Ltd }\end{array}$ \\
\hline [7] & $\begin{array}{l}\text { Cetin, A., Härkegard, G.: Fatigue life prediction for large threaded components. } \\
\text { Procedia Engineering } 2 \text { (2010) 1225-1233, Elsevier }\end{array}$ \\
\hline [8] & $\begin{array}{l}\text { Schneider, R., Wuttke, U., Berger, C.: Fatigue analysis of threaded connections using the } \\
\text { local strain approach. } \\
\text { Procedia Engineering } 2 \text { (2010) 2357-2366, Elsevier }\end{array}$ \\
\hline [9] & $\begin{array}{l}\text { Korin, I., Perez Ipiña, J.: Experimental evaluation of fatigue life and fatigue crack growth } \\
\text { in a tension bolt-nut threaded connection. } \\
\text { International Journal of Fatigue } 33 \text { (2011) 166-175, Elsevier }\end{array}$ \\
\hline [10] & $\begin{array}{l}\text { Korin, I., Perez Ipiña, J.:Controlled residual stresses introduction to improve fatigue } \\
\text { resistance of rotary shouldered connections used in oil drilling industry. } \\
\text { International Journal of Pressure Vessels and Piping } 87 \text { (2010) 696-703, Elsevier }\end{array}$ \\
\hline [11] & $\begin{array}{l}\text { Rust, W.: Nichtlineare Finite-Elemente-Berechnungen. } \\
\text { Vieweg+Teubner Verlag, 2. Auflage, } 2011\end{array}$ \\
\hline [12] & $\begin{array}{l}\text { Bauschinger, J.: Über die Veränderung der Elastizitätsgrenze und der Festigkeit des } \\
\text { Eisens und Stahls durch Strecken und Quetschen, durch Erwärmen und Abkühlen und } \\
\text { durch oftmals wiederholte Beanspruchung. } \\
\text { Mitt. Mech.-Techn. Lab. K. Techn. Hochsch. München, 13, S. 108-112, } 1986\end{array}$ \\
\hline [13] & $\begin{array}{l}\text { ANSYS Inc., Theory Manual: Rate independent plasticity, associated flow rule, } \\
\text { nonlinear/bilinear kinematic hardening }\end{array}$ \\
\hline [14] & $\begin{array}{l}\text { Hänel, B.; Haibach, E.; Seeger,T.: Rechnerischer Festigkeitsnachweis für } \\
\text { Maschinenbauteile aus Stahl, Eisenguss- und Aluminiumwerkstoffen. } \\
\text { VDMA Verlag, 5.Ausgabe, } 2003\end{array}$ \\
\hline
\end{tabular}


[15] $\quad$ Boller, C., Seeger, T.: Materials data for cyclic loading.

Part C: High alloy steels

Materials science monographs, 42C, Elsevier 